\title{
Dispositional mindfulness and cardiovascular reactivity to sensory rejection and sensory intake tasks
}

Paula R. Prentice

West Virginia University

Follow this and additional works at: https://researchrepository.wvu.edu/etd

\section{Recommended Citation}

Prentice, Paula R., "Dispositional mindfulness and cardiovascular reactivity to sensory rejection and sensory intake tasks" (2009). Graduate Theses, Dissertations, and Problem Reports. 4516.

https://researchrepository.wvu.edu/etd/4516

This Thesis is protected by copyright and/or related rights. It has been brought to you by the The Research Repository @ WVU with permission from the rights-holder(s). You are free to use this Thesis in any way that is permitted by the copyright and related rights legislation that applies to your use. For other uses you must obtain permission from the rights-holder(s) directly, unless additional rights are indicated by a Creative Commons license in the record and/ or on the work itself. This Thesis has been accepted for inclusion in WVU Graduate Theses, Dissertations, and Problem Reports collection by an authorized administrator of The Research Repository @ WVU. For more information, please contact researchrepository@mail.wvu.edu. 


\title{
Dispositional Mindfulness and Cardiovascular Reactivity \\ to Sensory Rejection and Sensory Intake Tasks
}

Paula R. Prentice

\author{
Thesis submitted to the \\ Eberly College of Arts and Sciences \\ At West Virginia University \\ in partial fulfillment of the requirements \\ for the degree of \\ Master of Science \\ In \\ Psychology
}

\author{
Kevin T. Larkin, Ph.D., Chair \\ Amy Fiske, Ph.D \\ Amy Gentzler, Ph.D \\ Department of Psychology \\ 2009 \\ Morgantown, WV
}

Keywords: mindfulness, meditation, heart rate variability, blood pressure, cardiovascular reactivity, stress 


\section{Abstract \\ Dispositional Mindfulness and Cardiovascular Reactivity \\ to Sensory Rejection and Sensor Intake Tasks \\ Paula R. Prentice}

Mindfulness is a trained or dispositional state of "being" that has been linked to positive mental and physical health effects. Although preliminary findings on cortical activation have shown mindfulness to be associated with increased frontal activation and reduced limbic activity, very little is known regarding the influence of mindfulness on autonomic nervous system activity. The present study sought to determine how participants varying in self-reported levels of dispositional mindfulness reacted to tasks differing on attention to environmental stimuli. Cardiovascular reactivity [heart rate, heart rate variability (HRV), and systolic and diastolic blood pressure] to a sensory intake task (computerized reaction time task) was contrasted with reactivity to a sensory rejection task (mental arithmetic). Forty students ( $71 \%$ women) were selected from a large sample of undergraduates and categorized as being high or low in dispositional mindfulness. Congruent with previous research, heart rates increased during the sensory rejection task and decreased during the sensory intake task $(p<.01)$. Additionally, significant differences between tasks were observed for high and low frequency HRV, with heart rate increases to sensory rejection being associated with increased low frequency HRV and heart rate decreases to sensory intake being associated with increased high frequency HRV ( $p \mathrm{~s}<.001)$. Though the proposed Mindfulness Level by Task Type interaction was not significant, results showed that systolic blood pressure reactivity differed between high and low levels of mindfulness $(p<.01)$, with higher systolic blood pressure reactions being associated with high levels of mindfulness. Further examination of mindfulness factors revealed that the Act with Awareness facet of mindfulness was significantly related to blood pressure reactivity during the 
sensory intake task, but not during the sensory rejection task, $r$ 's $=.40-.48, p$ 's $<.01$. Results also revealed that participants high in mindfulness performed much better on the sensory intake task than participants low in mindfulness, but these task performance differences did not explain the elevated blood pressure responses observed among high mindfulness participants. These results replicate and extend existing research reporting task differences in cardiovascular reactivity, indicating that reactivity to sensory rejection tasks is driven by the sympathetic nervous system, whereas reactivity to sensory intake tasks is primarily parasympathetic. Results relating mindfulness and reactivity to stress imply that acting with awareness may be one behavioral mechanism through which dispositional mindfulness influences physiology. 


\section{Acknowledgements}

I would like to thank my advisor and committee chairperson Kevin Larkin for his guidance in the design and completion of this study. Thank you, as well, to Amy Fiske and Amy Gentzler for their comments and suggestions as thesis committee members. I would like to thank all of the members of the Behavioral Physiology lab, especially Amanda Wheat and Matthew Whited for their guidance and support. Additionally, I would like to acknowledge Christine Kemmner, undergraduate research assistant, for her invaluable help with data collection. Finally, I would like to thank Aaron Riesbeck for designing the software program used in this study, and for priceless support and encouragement. 
Table of Contents

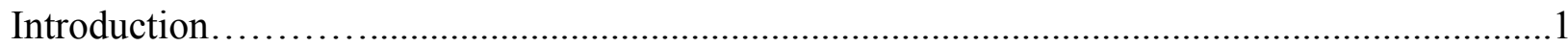

Mindfulness as an Effective Psychological Treatment...............................2

Dispositional Mindfulness...................................................5

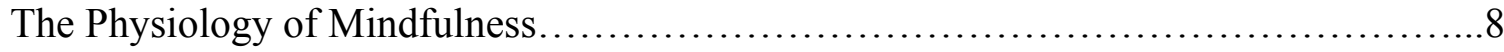

Cardiovascular Reactivity to Sensory Intake and Sensory Rejection Tasks..............13

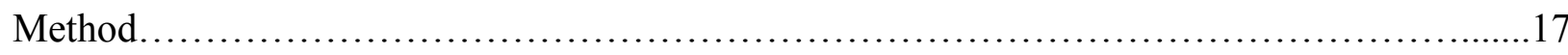

Participants and Sample Size................................................17

Cardiovascular Measures...................................................19

Experimental Measures.....................................................19

Experimental Tasks........................................................21

Procedure..................................................................... 21

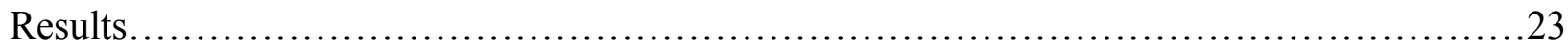

Data Preparation and Reduction...........................................23

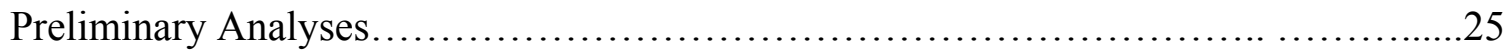

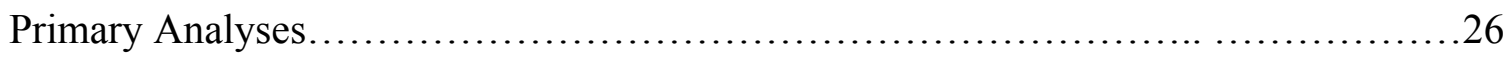

Additional Analyses on Other Physiological Measures..............................28

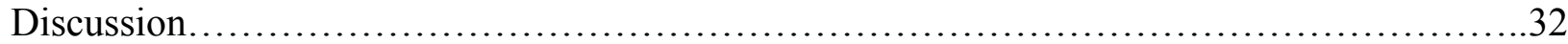

Sensory Intake and Rejection Task Differentiation............................... 32

Mindfulness and Cardiovascular Reactivity to Sensory Rejection and Sensory Intake...35

Mindfulness and Blood Pressure................................................. 36

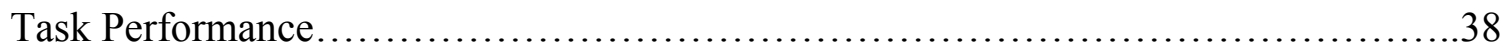

Mindfulness Factors and Reactivity to Tasks.................................... 38

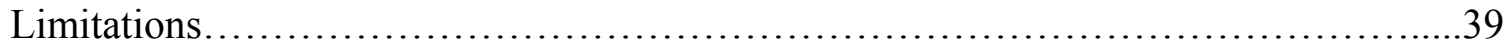

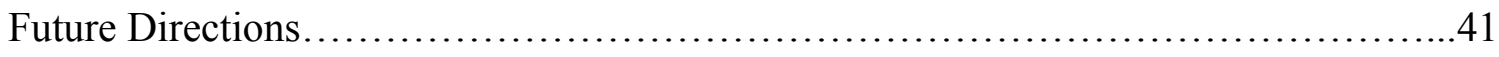

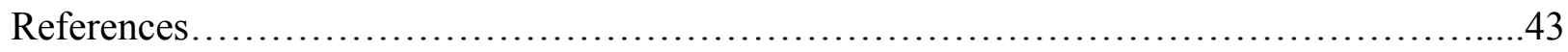

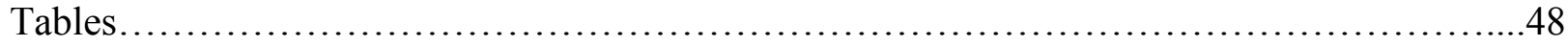

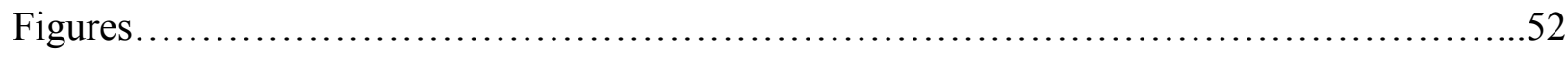

Appendices.............................................................. 53

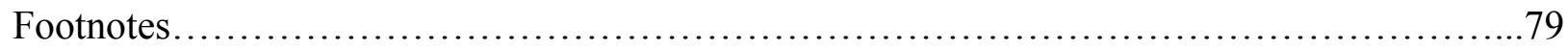

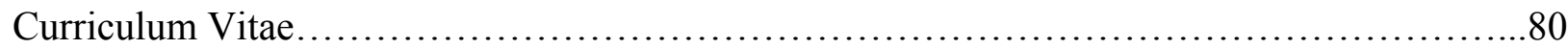




\section{Dispositional Mindfulness and Cardiovascular Reactivity to Sensory Rejection and Sensory Intake Tasks}

Unique among human cells are the neurons that comprise the cerebral cortex. These cells serve as fundamental building blocks for all human cognitive activity, including sensory-motor functioning, attention, information processing, emotional functioning, and the full array of higher cognitive functions like thinking, reasoning, problem solving, and creative thinking. Although behavioral neuroscientists are far from mapping the structures that underlie each of these cortical functions, significant progress has been made in this area over the past decade (e.g., Aron, Robbins, \& Poldrack, 2004). It is generally recognized that the rational, logical functions occur in distinctive cortical regions from the emotional and/or creative functions (Ochsner, Bunge, Gross, Gabrieli, 2002). Borrowing terminology and empirical findings from behavioral neuroscience, recent advances in scientific clinical psychology have distinguished the rational, logical cognitive functions of problem solving from the sensory functions associated with experiencing the current internal and external environment (e.g., Hayes, 2006; Kabat-Zinn, 1990; Linehan 1993). Colloquially, the former function of the brain has been referred to as 'doing,' and the latter as 'being.' In brief, 'doing' functions of the brain, including both worry about the future and rumination regarding the past, are associated with increased psychological stress, anxiety, and depression, whereas 'being' functions of the brain are associated with more positive emotional outcomes (e.g., Nolen-Hoeksema, Stice, Wade \& Bohon, 2007; Nyklicek \& Kuijpers, 2008).

The classic definition of this 'being' state, otherwise known as mindfulness, is "the awareness that emerges through paying attention on purpose, in the present moment, and nonjudgmentally to the unfolding of experience moment by moment" (Kabat-Zinn, 1990). 
Mindfulness has also been termed "heartfulness," as some would describe it as a "compassionate awareness" (Williams et al., 2007, p. 5). Recently, a two-fold operational definition of mindfulness was proposed: first, mindfulness involves "the self-regulation of attention so that it is maintained on immediate experience, thereby allowing for increased recognition of mental events in the present moment" while simultaneously adopting "an orientation that is characterized by curiosity, openness, and acceptance" toward the experiences occurring in the present moment (Bishop et al., 2004, p. 232). Although mindfulness has been described in a variety of ways, a common theme among these descriptions is the fundamental role of a heightened awareness of or increased attention toward the present moment.

\section{Mindfulness as an Effective Psychological Treatment}

The last quarter-century in clinical psychology has seen increased interest in the relation between level of awareness and psychological distress. Specifically, mindful awareness has been systematically implemented as a treatment for chronic pain, stress, depression, borderline personality disorder (Kabat-Zinn, 1990; Kabat-Zinn, Lipworth, \& Burney, 1985; Morone, Grecco, \& Weiner, 2008; Linehan, 1993; Segal, Williams, \& Teasdale, 2002; Williams, Teasdale, Segal, Kabat-Zinn, 2007), and written about as a potential treatment for other psychological disorders and physical illnesses (Siegel, 2007). Over the past decade, mindfulness-based interventions have risen from being categorized as complementary and alternative treatments to evidence-based interventions that represent front line therapeutic approaches for a range of clinical conditions that are frequently chosen by clinicians.

\section{Mindfulness Based Stress Reduction}

The most commonly cited model of mindfulness intervention is a stress reduction technique described and promoted by Jon Kabat-Zinn in 1990. This technique was introduced as 
a means of dealing with the stress of chronic pain related to illness and to reduce the risk of heart disease related to anger and aggression. Additionally, Kabat-Zinn (1990) intended this program for use in reducing panic, anxiety, and depression as well.

There is evidence that Mindfulness-Based Stress Reduction (MBSR) can significantly reduce symptoms of anxiety and panic in clinical populations. Kabat-Zinn and colleagues (1992) conducted a study of MBSR using 22 participants who had been diagnosed with generalized anxiety disorder or panic disorder using a DSM-III-R structured clinical interview. This study, which implemented a group stress-reduction program over the course of 8 weeks, was a pilot study of MBSR for anxiety, and a repeated measures design was implemented. The investigators found that participants experienced a significant reduction in anxiety throughout the treatment, and this reduction was maintained over a 3-month follow-up period (Kabat-Zinn et al., 1992).

Additionally, mindfulness therapy holds promise as a treatment for anxious children (Semple, Reid, \& Miller, 2005). In a recent pilot study, 5 children, aged 7 and 8 years, who were diagnosed with anxiety by a school psychologist, participated in a 6-week intervention trial during which they met with two therapists as a group for 45 minutes a week. Each week, the children were taught and practiced mindfulness in relation to the different physical senses, and were asked to practice their mindfulness activities as homework. The children were evaluated pre- and post-treatment using the Child Behavior Checklist - Teacher Report Form (Achenbach, 1991) and a self-report measure called the Multidimensional Anxiety Scale for Children (March, 1997), in addition to other measures. Improvements from pre- to post-treatment anxiety scores were reported for all 5 children (Semple, Reid, \& Miller, 2005). "By the end of six weeks, four of the five children demonstrated enthusiasm and interest in practicing mindfulness and requested that the group continue" (Semple, Reid, \& Miller, 2005, p. 387). 
In their 2004 study, Ramel, Goldin, Carmona, and McQuaid implemented MindfulnessBased Stress Reduction (Kabat-Zinn, 1990) as a treatment for depression. This manualized 8week treatment consisted of weekly 2-hour classes, a half-day meditation session at the $6^{\text {th }}$ week, and daily 45-minute guided meditation homework. This study included both a treatment group and a waitlist control group who later participated in the MBSR program. As they predicted based on mindfulness theory, Ramel and colleagues (2004) reported a negative correlation between hours of mindfulness meditation and rumination as measured by the Response Style Questionnaire (RSQ) within the treatment group. Additionally, when comparing the treatment group to the waitlist control group, the investigators reported an interaction on the rumination subscale of the RSQ. That is, while the rumination level of the treatment group decreased over the 8-week treatment period, rumination scores of the waitlist control group increased slightly (Ramel et al., 2004). This finding is consistent with the prediction that mindfulness meditation can be an effective component in reducing ruminative thoughts in individuals who have been diagnosed with depression.

\section{Mindfulness-Based Cognitive Therapy for Depression Relapse}

The major treatment related to mindful awareness currently in use for depression relapse prevention is Mindfulness-Based Cognitive Therapy (MBCT) (Segal, Williams, \& Teasdale, 2002), which is a combination of Mindfulness-Based Stress Reduction (Kabat-Zinn, 1990) and cognitive therapy for depression (Beck, Rush, Shaw, \& Emery, 1979). This method of treatment was created for those who have recovered from depression, to prevent relapse (Kenny \& Williams, 2007).

There is evidence that MBCT is effective in helping to prevent relapse in previously depressed individuals (Ma \& Teasdale, 2004). In a replication of their previous study, Ma and 
Teasdale (2004) demonstrated that MBCT reduced relapse rates from $78 \%$ to $36 \%$ in individuals with numerous previous episodes of major depression. This study involved 73 participants in an MBCT treatment group and 68 participants in a treatment-as-usual control group. The treatment group underwent an 8-week Mindfulness-Based Cognitive Therapy protocol, which met for 2 hours once a week and included mindfulness meditation homework exercises (Ma \& Teasdale, 2004). The percentage of relapse prevention reported in this study supported the prediction that MBCT was effective as a depression relapse-prevention treatment.

\section{Dispositional Mindfulness}

Many treatments that implement mindfulness, including Mindfulness Based Stress Reduction (MBSR; Kabat-Zinn, 1990) and Mindfulness-Based Cognitive Therapy (MBCT; Segal, Williams, \& Teasdale, 2002), emphasize formal mindfulness meditation practice. In fact, in their description of the MBCT course, Segal and colleagues (2002) describe formal meditation practice as "central and not an optional extra" (p. 118). This indicates that one must actively cultivate mindfulness skills through regular practice to develop a mature mindful awareness. Other treatments that incorporate some type of mindfulness training, such as Acceptance and Commitment Therapy (ACT; Hayes, Luoma, Bond, Masuda, \& Lillis, 2006) and Dialectical Behavior Therapy (DBT; Linehan, 1993), suggest implementing shorter mindfulness exercises rather than formal meditation.

Still other researchers in this field consider the possibility that individuals may acquire the skills generally described as mindfulness without any formal mindfulness meditation practice. This idea that mindfulness may be a "naturally occurring characteristic" (Brown \& Ryan, 2003, p. 822 ) is the impetus behind the development of many mindfulness self-report measures, which 
assess mindful behaviors. For example, the following items are a part of the Mindful Attention Awareness Scale (MAAS; Brown \& Ryan, 2003):

"I break or spill things because of carelessness, not paying attention, or thinking of something else," and

“I tend to walk quickly to get where I'm going without paying attention to what I'm experiencing along the way" (p. 826).

If an individual endorses these items as occurring often, they are considered to be less mindful than individuals endorsing them as occurring less frequently. The creators of self-report scales of mindfulness emphasize the fact that scores on self-report measures of mindfulness have been shown to improve following training in mindfulness meditation. This suggests that measures like the MAAS are valid tools for measuring the construct of mindfulness.

Investigators interested in "dispositional mindfulness" have attempted to develop measures that reliably predict which individuals behave in mindful ways, though these individuals may not have formal meditation experience. Part of the quest to understand mindfulness involves discovering the various facets of mindful awareness. Baer and colleagues (2006) analyzed five psychometrically sound mindfulness questionnaires in order to contribute to this search for a unified theory of mindfulness. The questionnaires included in this study were the Kentucky Inventory of Mindfulness Skills (KIMS; Baer, Smith, \& Allen, 2004), the Mindful Attention Awareness Scale (MAAS; Brown \& Ryan, 2003), the Freiburg Mindfulness Inventory (FMI; Walach, Buchheld, Buttenmuller, Kleinknecht, \& Schmidt, 2006), the Cognitive and Affective Mindfulness Scale (CAMS; Feldman, Hayes, Kumar, \& Greeson, 2004, as cited in Baer et al., 2006), and the Mindfulness Questionnaire (MQ; Chadwick, Hember, Mead, Lilley, \& Dagnan, 2005, as cited in Baer et al., 2006). 
A factor analysis of these five instruments resulted in a model of mindfulness composed of the following five factors: (1) nonreactivity to inner experience; (2) observing, noticing, attending to sensations, perceptions, thoughts, and feelings; (3) acting with awareness, automatic pilot, concentration, nondistraction; (4) describing, labeling with words; and (5) nonjudging of experience (Baer et al., 2006). It should be noted, however, that the "observe" factor did not load as an independent factor in a sample with little to no meditation experience (Baer et al., 2006). This is important as it may help distinguish between those facets of mindfulness that can be learned without formal practice and those that require some type of formal training to develop. This may also prove helpful when investigating mindfulness as a construct so one might control for level of meditation experience.

Knowledge of these factors should prove useful when implementing mindfulness as a treatment, since it was shown that three of the factors validly predicted psychological symptoms (Baer et al., 2006). Additionally, discovery of these factors is important for mindfulness researchers who may use this information to design studies investigating which facets of mindfulness are integral to improving treatment outcomes or promoting improved health. If certain benefits of being mindful are associated with a specific factor of mindfulness, it is critical to measure these distinctive factors in order to contribute to an improved theoretical understanding of mindfulness as well as interpret studies conducted across different laboratories. This is especially true when considering the effect mindfulness has on physiological measures, because it is possible that the physiological sequelae associated with the specific factors of mindfulness are distinctive. 
Though mindfulness has demonstrated beneficial treatment effects for a variety of medical and psychiatric conditions, the mechanism(s) through which these effects are bestowed is not yet clear. Presumably, persons who either possess high dispositional mindfulness or who complete training to enhance mindfulness exhibit different patterns of physiological arousal in response to stress than persons low in mindfulness, ranging from distinctive cortical and limbic system responses to stress to autonomic, neuroendocrine, and immunologic responses to stress. Although there have been numerous studies comparing physiological parameters among persons high and low in mindfulness (including studies on experienced mindfulness meditators), very little has been done examining the relation between measures of mindfulness and physiological responses to stress. The primary aim of the proposed project is to contribute to this surprisingly scant literature to better understand the association between mindfulness and physiological responses to stress.

A relatively recent empirical study (Creswell, Way, Eisenberger, \& Lieberman, 2007) that contributes greatly to our understanding of the stress physiology of mindfulness measured the neurological correlates of the "describing and labeling" factor that Baer and colleagues (2006) described. Individuals who are mindful are able to correctly label their present emotions, and by doing so, view their immediate emotional responses objectively and process affect without reacting immediately.

In this study, students with a range of scores on a measure of dispositional mindfulness completed an affect labeling and a control task while being scanned for cortical arousal using functional magnetic resonance imaging. Results showed mindfulness scores during affect labeling were associated with increased activation in the right ventrolateral prefrontal cortex and medial prefrontal cortex, and reduced activation in both right and left amygdalae (Creswell et al., 
2007). Connectivity analyses revealed that among individuals high in dispositional mindfulness, increased cortical activation occurring during affect labeling was strongly negatively correlated with amygdalae activation, suggesting that mindfulness resulted in emotion regulation through top-down cortical processing.

These results are made more salient to the present study when one considers a recent investigation into the relation between amygdalar activation and cardiovascular reactivity to stress (Gianaros et al., 2008). To examine this relation, Gianaros and colleagues asked participants to complete a Stroop color-word stressor task while measuring mean arterial pressure (MAP) and corticolimbic responding using functional magnetic resonance imaging (fMRI). Participants were shown color words written in either congruent or incongruent colors, and asked to identify the color in which the target word was shown. Participants rated the incongruent Stroop words as more stressful than the congruent words. The investigators reported significant correlations between right and left amygdalar activation and change in MAP during the incongruent stressor condition $(r=0.55$ and $r=0.47$ respectively, $p<.01)$. These results indicate that amygdalar activation is related to increased blood pressure reactivity to stress.

Gianaros and colleagues proposed that amygdalar function effects arterial pressure through its connection to the pre-autonomic areas of the pons. Connectivity between the amygdalae and the pons was examined in relation to change in MAP, and results revealed significant correlations between the amygdala-pons connectivity coefficient and change in MAP for both the right and left amygdalae ( $r=0.67$ and $r=0.66$ respectively, $p<.01$ ) (Gianaros et al., 2008). In conjunction with the findings from the study by Creswell and colleagues (2007), dispositional mindfulness has been shown to be inversely related to amygdalar activation, which in turn is linked to greater changes in mean arterial pressure during a stressor task. Presumably, 
then, mindfulness may be related to decreased cardiovascular reactivity to stress through its known association with reduced amygdalar reactivity to stress.

Creswell, Eisenberger, Taylor, and Seeman (2008) extended their fMRI study of mindfulness using a different task, a computer ball-tossing game in which study participants were asked to toss a computerized ball with two other players during functional magnetic resonance imaging. Two conditions were employed: ball tossing in which the participant was actively included, and ball tossing in which the other two players begin to toss the ball exclusively, socially isolating the participant. Results revealed that the dorsal anterior cingulate cortex was the part of the brain emotionally activated by social isolation. In this study, mindfulness scores were significantly negatively correlated with the magnitude of the dorsal anterior cingulate cortical responses $(r=-0.53)$, indicating that mindfulness modulated the emotional distress associated with social isolation. In a second study presented in this paper, Creswell and colleagues (2008) employed a standard psychosocial stressor, the Trier Social Stress Task, a commonly used laboratory stress manipulation that involves solving math problems and giving a speech in front of an audience. In this study, salivary cortisol responses to the task and during task recovery were significantly lower among participants with higher scores in mindfulness.

Acknowledging that mindfulness is associated with distinctive cortical responses to both affect labeling and social isolation, and that these differential responses influence neuroendocrine responses to standardized stress presentations, it is likely that mindfulness may also be related to distinctive responses of the autonomic nervous system. To examine the effects of one component of MBSR on the autonomic nervous system, Ditto, Eclache, and Goldman (2006) conducted two studies with similar methodologies. In both of these studies, effects of Body Scan 
Meditation, a basic component of mindfulness meditation treatments, were compared to a Progressive Muscle Relaxation condition and a control condition. Physiological measures taken included blood pressure, heart rate, general heart rate variability, and variability associated with respiration (respiratory sinus arrhythmia, or RSA). Participants were measured at baseline, then immediately thereafter while practicing their technique for the first time (or, in the case of the control group, continuing to sit). Participants either completed one whole Body Scan Meditation, or 20 minutes of a Progressive Muscle Relaxation exercise. Then, participants were given materials to read and assignments to practice over a period of 1 month, after which the experimental procedure was repeated.

Results of the first study indicated no significant effect of Body Scan Meditation on either resting systolic or diastolic blood pressure when compared to either the PMR or wait-list control groups. However, ANOVAs conducted on the respiratory sinus arrhythmia data revealed significant Group x Time and Session x Time interactions. The results showed "that individuals who practiced mindfulness meditation displayed significantly larger baseline to treatment increases in RSA than participants in both the sitting quietly and progressive muscular relaxation conditions in both sessions" (Ditto et al., 2006, p. 229).

In the second study, additional measures of autonomic activity were taken to better understand the effects of mindfulness meditation on physiology. Other measures used in this study included measures of total peripheral resistance and cardiac pre-ejection period (PEP), which is "perhaps the best noninvasive measure of cardiac sympathetic activity" according to the authors (Ditto et al., 2006, p. 230). The methodology of this study differed slightly from the first study, in that the control participants listened to an audio novel instead of participating in PMR training. Similar to Study 1, results indicated no significant effect of condition on resting heart 
rate or blood pressure. As in Study 1, there was a significant treatment effect on RSA;

participants who meditated "displayed greater increases in RSA" than those listening to the audio novel (Ditto et al., 2006, p. 230). In addition, results revealed increases in heart rate variability and PEP for meditators, which the investigators used to support the idea that meditation may also result in increased cardiac sympathetic activity.

Although only a few studies have examined autonomic, neuroendocrine, or cortical influences of mindfulness, the evidence that exists supports the hypothesis that mindfulness is associated with distinctly unique patterns of physiological arousal. Both the work of Creswell and colleagues employing students with varying levels of dispositional mindfulness and Ditto and colleagues' work examining persons undergoing mindfulness interventions support this hypothesis. For the most part, however, studies that comprise this literature have aimed to measure physiological states during periods of rest and only a few have measured physiological responses during presentations of stress. This is somewhat surprising given that a multitude of experimental stress manipulation paradigms have been developed and that MBSR was initially devised as a stress management intervention.

There is literally over a half a century of empirical work examining various types of task manipulations used in psychophysiological research (Lacey, Kagan, Lacey, \& Moss, 1963; Lacey \& Lacey, 1970; Williams, Bitker, Buchsbaum, \& Wynne, 1975), and while it is beyond the scope of this paper to review this body of literature comprehensively, task dimensions may be particularly important to consider when examining the relation between mindfulness and physiological responses to stress. For example, one of the most common mental stress manipulations used in psychophysiological studies is mental arithmetic, typically serial subtraction. To complete this task successfully, participants must concentrate entirely on mental 
processing and ignore all distractions from the immediate external environment. In contrast, reaction time tasks require participants to focus attention to specific visual or auditory stimuli so a quick response can be made when stimuli are detected. Patterns of physiologic response associated with mindfulness may look quite different if evaluated using mental arithmetic or reaction time mental stress manipulations. Interestingly, John and Beatrice Lacey recognized this decades ago when they described the differences in physiological response patterns for sensory rejection tasks like mental arithmetic and sensory intake tasks like reaction time tasks (Lacey, Kagan, Lacey, \& Moss, 1963; Lacey \& Lacey, 1970).

Cardiovascular Reactivity to Sensory Intake and Sensory Rejection Tasks In a series of studies reported in 1963, Lacey, Kagan, Lacey, and Moss were interested in what they termed "stimulus or situational stereotypy of response" (p. 163). These studies were investigations into cardiovascular reactions to a range of stimulus conditions. The investigators' interest in stimulus-specific responding stemmed from their accidental discovery of a phenomenon called "directional fractionation of response" (Lacey et al., 1963, p. 164). The term "fractionation" referred to instances in which individuals' autonomic responses to certain stimuli seemed to be going in opposite directions (e.g., increased skin conductance accompanied by cardiac deceleration). This fractionation usually occurred in response to tasks in which the participant was asked to attend to external visual or auditory stimulation. However, if a participant was assigned a task that required increased concentration on internal events, then this seemed to result in both cardiac acceleration and an increase in other measures of autonomic activity, such as skin conductance (Lacey et al., 1963). These results inspired Lacey and colleagues to further investigate cardiovascular reactivity to different tasks requiring varying levels of attention to the external environment. In these studies, they hypothesized that cardiac 
deceleration "accompanied and perhaps even facilitated 'ease of environmental intake,' whereas cardiac acceleration accompanied or facilitated 'rejection of the environment' " (Lacey et al., 1963, p. 165).

The tasks which Lacey and colleagues employed ranged from attending to environmental inputs, "like photic flashes or white noise, or a dramatic recitation with which [the participant] was asked to empathize, to tasks like mental arithmetic, reversed spelling, [making] up sentences, and...the cold-pressor test" (Lacey \& Lacey, 1970, p. 210). The wide range of tasks utilized in these studies was especially important to discovering more about this fractionation phenomenon.

The major difference between these two types of stimuli is whether the individual attends to their internal (mental) or external environment when presented with the task. Those tasks during which the participant was likely to, or even required to, attend to the environment, Lacey termed "sensory intake" tasks. Conversely, if it was unlikely that an individual would attend to external events while completing the task, it was labeled a "sensory rejection" task. These tasks were further differentiated by the participants' change in heart rate from a resting level when participating in the task. Significant cardiac decelerations were found during tasks that required “only simple environmental reception” (Lacey \& Lacey, 1970, p. 211). As follows, during those tasks that required a participant to "reject" the external environment, or if a participant underwent aversive stimulation such as the cold-pressor task, cardiac acceleration resulted (Lacey \& Lacey, 1970).

These results were replicated and extended by Williams, Bitker, Buchsbaum, and Wynne (1975). In this study, participants' blood pressure, heart rate, forearm blood flow, digital pulse volume, and forearm vascular resistance were determined over a total of 6 intervals, 3 baseline measurements, and 3 task conditions. The sensory intake condition was a word identification 
task, in which participants were asked to identify one of 20 words projected blurred, backwards, and upside down onto a screen. A mental arithmetic task was used as the sensory rejection task in which participants subtracted by 12 s from 1,179 serially while being timed. Finally, an interview was conducted asking the participants about themselves and their family. This acted as a mixed sensory intake and rejection task.

Results demonstrated statistically significant differences in physiological measures between baseline and task conditions. A comparison between task conditions resulted in significant differences in all cardiovascular measures except heart rate. These differences were in the expected direction; that is, systolic and diastolic blood pressure decreased significantly during the word identification task compared to the other tasks, and the opposite was true of the mental arithmetic task (Williams et al., 1975). Interestingly, during the mixed sensory intake and rejection task, the physiological response pattern seemed to fall between those of the two individual tasks. This effect was also observed by Lacey and colleagues (1970) in their previous studies while measuring heart rate. The authors claimed "heart rate seems to be a sort of a vectorial resultant of at least these two apparently opposing demands on the cardiovascular system” (Lacey \& Lacey, 1970, p. 212).

\section{Statement of the Problem}

After examining the body of literature contrasting sensory intake and sensory rejection tasks, it is apparent that some similarities exist between the descriptions of what is termed a "sensory intake" task and certain facets of mindfulness. Namely, the behaviors in which one is engaging while completing a sensory intake task (directing attention to the external environment) bear close resemblance to the behaviors described in the "observe, notice, attend to sensations, perceptions, thoughts, and feelings" facet of mindful awareness. Additionally, these tasks require 
that one be present, and not daydreaming, so they may also reflect behaviors characterized in the “acting with awareness, non-automatic pilot, concentration, nondistraction" factor (Baer et al., 2006). However, the relation between dispositional mindfulness and reactivity to sensory intake and rejection tasks has not yet been explored. The purpose of the proposed study is to examine the association between dispositional mindfulness and cardiovascular response to presentations of both a sensory intake and sensory rejection task.

In examining the relation between mindfulness and measures of cardiovascular functioning, it is important to use mental tasks in contrast to resting parameters used in previous investigations of cardiovascular measures during meditation (e.g., Ditto et al., 2006). This is especially true when attempting to measure the positive health effects of mindfulness. In their review of behavioral approaches to the treatment of hypertension, Blumenthal and colleagues (2002) emphasized the value of laboratory stress tests to evaluate treatments when they stated that "mental-stress testing may... be considered a novel and potentially useful procedure for assessing BP in studies evaluating the effectiveness of interventions in patients with [hypertension]" (Blumenthal et al., 2002). In contrast to the previous empirical work in this area, the proposed study will examine the association between dispositional mindfulness and cardiovascular response to stress during standard sensory rejection (i.e., serial subtraction) and sensory intake (i.e., reaction time) tasks.

\section{Hypotheses}

Preliminary Analysis. Preliminary analyses were done to verify that heart rate reactivity to sensory intake and sensory rejection tasks differed congruent with the findings previously reported by Lacey and colleagues (Lacey, Kagan, Lacey, \& Moss, 1963; Lacey \& Lacey, 1970). More specifically, across all study participants, analyses were conducted to verify that the 
sensory intake task employed in this study resulted in decreased heart rate responses, in contrast to the sensory rejection task that resulted in increased heart rate responses.

Hypothesis 1. In their recent research, Creswell and colleagues (2008) found that mindfulness skills acted as a buffer against neuroendocrine reactivity to an affect labeling task. Extending this research to autonomic outcomes, a mindfulness group by task interaction was hypothesized. More precisely, it was hypothesized that individuals in the high dispositional mindfulness group would show less heart rate acceleration during a sensory rejection task when compared with individuals in the low mindfulness group. Because the act of being mindful approximates the mental state associated with sensory intake, it was hypothesized that individuals in the high dispositional mindfulness group would display greater reductions in heart rate and blood pressure during the sensory intake task than those individuals classified as low in dispositional mindfulness.

Hypothesis 2. Based upon the findings of Ditto and colleagues (2006), it is highly likely that alterations in measures of sympathetic and/or parasympathetic nervous system activity will be observed both with respect to the nature of the two tasks employed in this study and the hypothesized mindfulness level by task interaction. It was hypothesized that parasympathetic activity, as measured via heart rate variability, would be enhanced during the sensory intake task in comparison to the sensory rejection task among all participants. Second, it was proposed that participants high in dispositional mindfulness would exhibit greater parasympathetic activation to the tasks than participants low in dispositional mindfulness.

Method

Participants and Sample Size 
Participants were 40 undergraduate students (71\% women) enrolled in Psychology courses at West Virginia University who were recruited using the SONA system. Based on the sample size used by Creswell and colleagues (2007), analyses indicated that 40 participants would provide adequate power with which to detect a comparable effect. Participants were excluded if they had a history of chronic health problems (e.g., heart disease, respiratory disease, etc...), smoked or used smokeless tobacco at least once daily, or were currently taking any medications that affected heart rate or blood pressure (e.g., beta blockers). Average participant age was 19.3 years $(S D=1.66)$. According to participant self-report of race, the sample was 89.5\% Caucasian, with one person representing each of the following: Black, Hispanic, Biracial, and Other.

One thousand two hundred twenty-nine potential participants were screened using the MAAS for participation in this study, resulting in a relatively normal distribution with a mean of 56.26 and a standard deviation of 12.4. Participants scoring in the upper third of the distribution (i.e., scores $>60$ ) were categorized as high in dispositional mindfulness, and participants scoring in the lower third of the distribution (i.e., scores $<52$ ) were categorized as low in dispositional mindfulness (see Figure 1 for a diagram of participant categorization and screening). Experimental Design

The current study employed a 2 by 2 mixed factors design, in which the within subjects factor is Task Type (Sensory Intake; Sensory Rejection) and the between subjects factor is Mindfulness Level (High; Low). The dependant variables were heart rate (beats per minute [bpm]), blood pressure ( $\mathrm{mm} \mathrm{Hg}$ ), and heart rate variability (in log units and percent), as well as reaction time (seconds $[\mathrm{s}]$ ) during the sensory intake task, and number of subtractions completed during the sensory rejection task. 


\section{Cardiovascular Measures}

Heart rate was continually monitored during the experiment utilizing a Polar heart rate monitor Model RS800 (Lake Success, New York). This device consists of a sensor that detects ECG signals and is strapped around the participant's chest and a wrist watch receiver that was connected to a computer. This computer was located in an observation room where the experimenter monitored data acquisition. Continuous strings of interbeat intervals were generated for each rest and task period; these data were subjected to spectral analysis for purposes of determining mean heart rate and heart rate variability for each task period using the Kubios HRV Analysis Software program. The HRV Analysis Software program has been shown to estimate valid parameters of heart rate and heart rate variability (Niskanen, Tarvainen, Rantaaho, \& Karjalainen, 2002). This software program derived the following measures of HRV: low frequency (LF) HRV, a measure of both sympathetic and parasympathetic activity that reflects baroreceptor activity; high frequency (HF) HRV, a measure of parasympathetic activity of the vagal nerve; and the square root of the mean squared difference of beat-to-beat intervals (RMSSD), an overall measure of heart rate variability.

In order to measure blood pressure (systolic, diastolic, and mean), an IBS SD-700A automated sphygmomanometer (Waltham, MA) was employed. This device measures blood pressure via an occluding cuff that contains a microphone for detecting Korotkoff sounds. This cuff was positioned on the participant's non-dominant arm so that it did not interfere with movement during the reaction time task. Measures of SBP and DBP were displayed digitally and recorded by the experimenter. MAP was calculated using the formula: $\mathrm{MAP}=((\mathrm{SBP}-\mathrm{DBP}) / 3)$ + DBP. Experimental Measures 
Demographics. Participants completed a questionnaire asking relevant demographic information (age, sex, socioeconomic status, etc.), health history, and health behavior information (see Appendix A).

Mindful Attention Awareness Scale. The MAAS (Brown \& Ryan, 2003) is a measure of mindfulness comprised of fifteen items that participants rated on a 6-point frequency scale (see Appendix B for a copy of the MAAS). The MAAS indirectly measures mindfulness skills by asking the frequency of mindless experiences (e.g., breaking or spilling things, or running on automatic pilot) where a higher score indicates a less frequent occurrence, thus indicating higher mindfulness. This measure has demonstrated high reliability (Cronbach's $\alpha=.87$ ) when administered to populations with and without mindfulness training. Additionally, the MAAS has been shown to differentiate between individuals who actively meditate and those with no meditation experience $(M=4.38(0.65)$, and $M=3.95(0.61)$, respectively). This measure was utilized to differentiate between persons with varying levels of mindfulness in recent studies of mindfulness and stress physiology (e.g., Creswell et al., 2007).

Five Facet Mindfulness Questionnaire. The Five Facet Mindfulness Questionnaire (FFMQ; Baer et al., 2006) is a 38-item measure that was created to measure several aspects of mindfulness. Five existing mindfulness questionnaires were administered to 613 undergraduate students and the results were subjected to exploratory factor analysis. Confirmatory factor analysis of the data collected from another sample of 268 undergraduates confirmed the original five-factor structure. As noted in the Introduction, the measures included in this analysis were the KIMS (Baer, Smith, \& Allen, 2004), the MAAS (Brown \& Ryan, 2003), the FMI (Walach, Buchheld, Buttenmuller, Kleinknecht, \& Schmidt, 2006) the CAMS (Feldman, Hayes, Kumar, \& Greeson, 2004, as cited in Baer et al., 2006), and the MQ (Chadwick, Hember, Mead, Lilley, \& 
Dagnan, 2005, as cited in Baer et al., 2006). The measure has demonstrated high reliability, as well as the ability to differentiate between individuals with and without mindfulness meditation experience.

Experimental Tasks.

Sensory Rejection Task. This task involved mental arithmetic, which is a common laboratory stressor that encourages rejection of environmental stimuli. In this task, participants were asked to subtract 7 serially from 9,000 for a period of 5 minutes. Participants' responses were recorded for later scoring. Task performance was lost for nine participants due to recording equipment failure. Number of correct subtractions was divided by number of attempted subtractions and multiplied by 100 to obtain a measure of percentage of correct subtractions.

Sensory Intake Task. To encourage sensory intake, participants completed a reaction time task in which they were asked to differentiate between numbers and letters that appeared on a monitor. Instructions indicated that participants should press the "L" key if the image is a letter, or the "N" key if a number appeared on the monitor. Stimuli were presented on a lap top computer on a portable lap top stand positioned in front of the participant. Each participant was asked to enter their SONA systems ID number into the space provided, to read the task instructions on the screen (Appendix D), and to check a box indicating that they had read the instructions before beginning the task. To measure task performance, participant reaction times (in ms) and accuracy were recorded.

\section{Procedure}

Screening. Following informed consent, participants were asked to complete demographic and mindfulness self-report questionnaires using the SONA system. Distributions of dispositional mindfulness scores on the Mindful Attention Awareness Scale (MAAS) were 
examined and individuals who scored in the upper and lower third of the distribution (indicating those with the highest and lowest dispositional mindfulness level) were invited to participate in the laboratory session. For these participants, the following laboratory procedure was then implemented.

Rest Period. Participants were greeted by the experimenter and given a brief summary of the study. Then, they were informed that their participation in this study was voluntary and may advance the understanding of psychological constructs. If a participant agreed to take part in this phase of the study, he or she was asked to sign a statement of informed consent which also explained that any identifying health information would be handled confidentially. Next, participants were escorted to an experimental room in the Behavioral Physiology Laboratory. They were instructed how to secure the Polar monitor sensor to their chest, after which the experimenter left the room. When the participant had the sensor in place, he or she alerted the experimenter, who then tested the device to ensure that the monitor was functional. Next, the participant was seated in the chair to which the Polar monitor wristwatch was fastened, and the occluding cuff was positioned over the brachial artery of the participant's non-dominant arm. Participants were instructed to keep their feet flat on the floor for a 15 minute rest period. Blood pressure measurements began 8 minutes into the rest period, and were taken every two minutes after that.

When the rest period ended, the experimenter gave instructions for the first task which was either the Sensory Rejection Task or the Sensory Intake Task. Task presentation was counterbalanced, with half of the study participants receiving the sensory rejection task first and the remaining half receiving the sensory intake task first. Blood pressure measurements were taken beginning at minute 0 and every two minutes throughout the duration of both tasks. 
Following each task, participants completed a stress rating of the task on the 4-point scale $(0=$ not at all stressful, 3 = extremely stressful) that was utilized by Gianaros and colleagues (2008). This same sequence was employed for presentation of the intervening rest period and remaining task.

When participants completed both tasks, the experimenter removed the occluding cuff, and left the monitoring room to allow the individuals to remove the Polar sensor. At the completion of the study, participants were debriefed regarding the purpose of the study. All participants received extra credit in their psychology class.

\section{Results}

\section{Data Preparation and Reduction.}

Blood pressure and heart rate (SBP, DBP, and HR) were averaged across each fiveminute period (pre-reaction time rest, reaction time, pre-mental arithmetic rest, mental arithmetic) to prepare data for analyses. Mean arterial pressure (MAP) for each period was calculated. Data to be used for heart rate variability analyses (IBIs) remained in five-minute segments, as longer time intervals are associated with more reliable measurement of HRV (Berntson et al., 1997).

Blood Pressure. Before completing analyses, data were examined to ensure that all blood pressure measurements fell within the criteria outlined by Marler and colleagues (1988). These criteria indicate that SBP measurements greater than $250 \mathrm{mmHg}$ or less than $70 \mathrm{mmHg}$ and DBP measurements greater than $150 \mathrm{mmHg}$ or less than $45 \mathrm{mmHg}$ should be excluded from analyses. Additionally, Marler and colleagues suggest eliminating measurements in which the difference between SBP and DBP is too small to be an accurate measurement of normal pressure. The data for the present study were visually examined for consistency across measurement periods, and 
subjected to tests of the Marler criteria to verify valid measurement. In the present study, $1 \mathrm{SBP}$ (.1\% of all SBPs measured) measurement and 2 DBP (.3\% of all DBPs measured $)$ measurements fell outside of the specified guidelines. These measurements were replaced with the mean of the SBP or DBP measures for the remaining minutes of that period.

Heart Rate. Heart rate data were examined prior to data reduction. Data were cleaned using the Polar program error correction feature. The error correction tool works by substituting abnormally high or low, invalid heart rate measurements with measurements that more accurately approximate heart rate at that time. Heart rate was collected continuously throughout each of the four periods (pre-reaction time rest, reaction time, pre-mental arithmetic rest, and mental arithmetic). For each five-minute period, approximately 315 measurements of heart rate occurred per participant. On average, records from five heart beats were replaced in each period, resulting in a very small proportion (approximately $1.59 \%$ ) of substitutions per participant.

Heart Rate Variability. Data for heart rate variability analyses were obtained from measures of time between heart beats [interbeat intervals (IBI)(ms)] collected using the Polar monitor. Simultaneously with heart rate data, IBI data were cleaned using the error correction application described above. Similar numbers of IBI's were corrected with this tool. Heart rate variability was measured continuously throughout each five-minute measurement period.

Normality and Missingness. When testing for normality, Tabachnick and Fidell (2001) suggest that measurements of three or above for skewness and ten or above for kurtosis are problematic. Tests of normality for all independent and dependent variables showed normal distributions for all self-report and physiological data. Additionally, any variable with more than $5 \%$ missingness should be considered problematic. None of the variables used in the following analyses were missing 5\% or more. Therefore, no data transformations were necessary. 
Dispositional Mindfulness 25

\section{Preliminary Analyses}

Order Effects. To determine if the order of task presentation significantly influenced any outcome variable, order effects analyses were conducted on all dependent measures (HR, RRms, SBP, DBP, MAP, LF HRV, HF HRV, RMSSD). Results of one-way ANCOVAs, controlling for pre-task resting measurements of each variable, revealed no significant differences among participants who completed the sensory rejection and sensory intake tasks in a different order (all $p$ 's $>$.05) (see Tables in Appendix E).

Task Effects. According to previous research (e.g., Lacey et al., 1963) mental arithmetic (sensory rejection) tasks should result in an increase in heart rate, and reaction time (sensory intake) tasks should result in a moderate decrease in heart rate. To test these effects, a one-way analysis of covariance (ANCOVA) was conducted on heart rate. Resting measures for each task were covaried to control for the relative effects of resting heart rate on heart rate reactivity. ${ }^{1}$ Results indicated a significant difference in heart rate reactivity to tasks, $F(1,35)=154.35, p$ $<.001, p \eta^{2}=.82$. Examination of mean heart rates showed that, when participants were engaged in the mental arithmetic task, heart rate increased from rest period $(M=77.47 \mathrm{bpm}, S D=10.08)$ to task $(M=85.15 \mathrm{bpm}, S D=10.05)$. In contrast, when participants were completing the reaction time task, heart rate decreased from rest period $(M=77.00 \mathrm{bpm}, S D=10.21)$ to task $(M=76.07$ bpm, $S D=9.78$ ). Thus, preliminary analyses confirmed that tasks produced the effect required to test the following hypotheses.

Group Differences. Participants in the high and low mindfulness groups were compared on all resting cardiovascular measures, as well as other variables that might influence the outcome variables. A $\chi^{2}$ analysis was used to compare the groups on gender. Results showed no significant group difference on gender, $\chi^{2}(1)=.21, p=.65$. Results of one-way ANOVAs 
revealed that the groups differed significantly on measures of mindfulness but did not differ based on age or resting cardiovascular parameters (see Table 1).

Primary Analyses

Hypothesis 1: Mindfulness by Task Interaction for Heart Rate. It was hypothesized that individuals high in dispositional mindfulness would show less heart rate acceleration during the sensory rejection task and greater heart rate deceleration during the sensory intake task when compared with individuals low in dispositional mindfulness. To test this, we employed a 2 (Task Type: Sensory Intake vs. Sensory Rejection) by 2 (Mindfulness Level: High vs. Low) analysis of covariance (ANCOVA) in which pre-task resting heart rate was covaried to control for the effects of resting heart rate on heart rate reactivity (See Table 2 for dependent variable means and standard deviations). Results showed that the Mindfulness by Task Type interaction was not significant for heart rate as measured by the Polar monitor, $F(1,35)=2.29, p=.14, p \eta^{2}=.06$ (See ANCOVA Summary Table in Appendix F).

Heart rate was also measured using IBIs that were entered into Kubios HRV analysis program (Niskanen et al., 2002). This program also reports heart rate using IBI (called R-R interval in the Kubios program) for each five-minute measurement period (e.g., rest, tasks). The average R-R intervals were also analyzed using a Task Type by Mindfulness Level ANCOVA. Results showed a significant main effect for Task Type, $F(1,35)=113.89, p<.001, p \eta^{2}=.77$, but no significant main effect for Mindfulness Level, $F(1,35)=.48, p=.49, p \eta^{2}=.01$, or Task Type by Mindfulness Level interaction, $F(1,35)=3.49, p=.07, p \eta^{2}=.09($ See ANCOVA Summary Table in Appendix F).

Hypothesis 2: Heart Rate Variability Main Effects. It was hypothesized that parasympathetic activity, measured via heart rate variability, would be enhanced during the 
sensory intake task in comparison to the sensory rejection task among all participants. Second, it was proposed that participants high in dispositional mindfulness would exhibit greater parasympathetic activation to the tasks than participants low in dispositional mindfulness. This hypothesis was also tested using a Task Type by Mindfulness Level ANCOVA, controlling for pre-task resting measures, on dependent measures of high and low frequency heart rate variability.

Low Frequency Heart Rate Variability. Results indicated that Hypothesis 2 was partially confirmed for LF HRV. Results showed a significant main effect for Task Type, $F(1,35)=19.3$, $p<.001, p \eta^{2}=.36$. Comparison of group means indicated that LF HRV reactivity was greater for the mental arithmetic task than the reaction time task. For the mental arithmetic task, LF HRV increased from rest period $(M=28.84 \%, S D=11.02)$ to task $(M=46.41 \%, S D=14.54)$. For the reaction time task, LF HRV remained the same from rest period $(M=33.81 \%, S D=12.46)$ to $\operatorname{task}(M=33.36 \%, S D=13.07)$. Main effect for Mindfulness Level and the Task Type by Mindfulness interaction were not significant, $F(1,35)=2.76, p=.11, p \eta^{2}=.08$, and $F(1,35)=$ $1.31, p=.26, p \eta^{2}=.04$ (See ANCOVA Summary Table in Appendix F).

High Frequency Heart Rate Variability. Results of HF HRV analyses also partially supported Hypothesis 2. Similarly to LF HRV, results showed a significant main effect for Task Type, $F(1,35)=29.10, p<.001, p \eta^{2}=.46$. In contrast to findings on LF HRV, HF HRV reactivity was greater for the reaction time task than the mental arithmetic task. During the mental arithmetic task, HF HRV showed no change from baseline $(M=24.01 \%, S D=19.91)$ to task $(M=23.85 \%, S D=11.10)$. For the reaction time task, HF HRV showed a significant increase from baseline $(M=24.01 \%, S D=19.91)$ to task $(M=36.07 \%, S D=18.32)$. As with LF HRV, the main effect for Mindfulness Level and the Task Type by Mindfulness interaction were 
not significant, $F(1,35)=.43, p=.52, p \eta^{2}=.01$, and $F(1,35)=1.68, p=.20, p \eta^{2}=.05$ respectively (See ANCOVA Summary Table in Appendix F). Additional Analyses on Other Physiological Measures

Although no specific hypotheses were made regarding measures of blood pressure and the remaining HRV measure, additional Task Type by Mindfulness Level ANCOVAs were conducted to examine whether dispositional mindfulness influenced reactivity to the two tasks for each of these cardiovascular parameters.

Systolic Blood Pressure. Results indicated a significant main effect for Task Type for $\mathrm{SBP}, F(1,35)=52.65, p<.001, p \eta^{2}=.61$, as well as a significant Mindfulness Level main effect, $F(1,35)=11.98, p<.01, p \eta^{2}=.26$. Further examination of means revealed that SBP reactivity was greater for the group with higher mindfulness levels than the group with lower mindfulness levels across tasks. Additionally, greater SBP reactivity was observed for the mental arithmetic task than the reaction time task. There was no significant Mindfulness Level by Task Type interaction for SBP, $F(1,35)=.58, p=.45, p \eta^{2}=.02$ (See means and standard deviations in Table 2 and the ANCOVA Summary Table in Appendix F).

Diastolic Blood Pressure. Results indicated a significant main effect for Task Type for DBP, $F(1,35)=17.47, p<.001, p \eta^{2}=.35$. Similar to SBP, DBP measurements during the mental arithmetic task were higher than those during the reaction time task. The main effect for Mindfulness Level and the Mindfulness Level by Task Type interaction were not significant, $F$ $(1,35)=.02, p=.90, p \eta^{2}=0$, and $F(1,35)=3.61, p=.07, p \eta^{2}=.10$, respectively (See ANCOVA Summary Table in Appendix F).

Mean Arterial Pressure. Results showed a significant main effect for Task Type for MAP, $F(1,35)=36.98, p<.001, p \eta^{2}=.52$, with MAP during the mental arithmetic task being 
higher than MAP during the reaction time task. However, the main effect for Mindfulness Level and the Mindfulness Level by Task Type interaction were not significant, $F(1,35)=.96, p=.33$, $p \eta^{2}=.03$, and $F(1,35)=1.27, p=.27, p \eta^{2}=.04$, respectively (See ANCOVA Summary Table in Appendix F).

$R M S S D$. Results indicated a significant main effect for Task Type for $\operatorname{RMSSD}, F(1,35)$ $=14.54, p<.001$. As described in the methods section above, RMSSD is an overall measure of heart rate variability that is thought to primarily reflect the activity of the parasympathetic nervous system. Further examination of the means revealed that RMSSD decreased from rest $(M$ $=43.03, S D=33.41)$ to task $(M=38.47, S D=25.82)$ during the mental arithmetic challenge and increased from rest $(M=46.99, S D=39.39)$ to task $(M=50.50, S D=38.90)$ during the reaction time task (See ANCOVA Summary Table in Appendix F).

\section{Task Performance}

Mental Arithmetic. Groups (high vs. low mindfulness) were compared on number of subtractions completed and percent subtractions correct. Results of two independent sample ttests revealed no significant differences for number of subtractions completed or percent correct between groups high and low in mindfulness, $t(30)=-.62, p=.54, d=-.23$, and $t(30)=-.63, p$ $=.53, d=-.23$, respectively.

Reaction Time. Groups (high vs. low mindfulness) were compared on reaction time (in seconds), number of reaction time trials completed, and answer accuracy. Results of three independent sample t-tests revealed a significant difference in reaction time, $t(36)=-2.06, p$ $<.05, d=-.69$, and number of reaction time trials completed, $t(36)=2.35, p<.05, d=.78$. No significant difference was found for percent trials correct, $t(36)=1.08, p=.29, d=.36$. Further examination of reaction time means revealed that persons high in self-reported dispositional 
mindfulness had faster reaction times $(M=.68 \mathrm{sec}, S D=.12)$ compared to those with low mindfulness levels $(M=.90 \mathrm{sec} ., S D=.43)$. Additionally, persons high in mindfulness completed more reaction time trials than those with lower mindfulness scores $(M=54.58, S D=$ 1.92 , and $M=52.42, S D=3.53$, respectively).

Subjective Rating of Stress

Participants rated both tasks on level of subjective stress $(0=$ least stressful to $3=$ most stressful). A Task Type by Mindfulness Level ANOVA was performed to examine mean differences on subjective stress. Results revealed a significant main effect for Task Type, $F$ (1, $35)=113.69, p<.001, p \eta^{2}=.77$, for subjective stress level. Further examination of means indicated that participants rated the sensory rejection task (mental arithmetic) as significantly more stressful than the sensory intake task (reaction time) $(M=2.02, S D=.87$, and $M=.64, S D$ $=.52$, respectively). The main effect for Mindfulness Level and Task Type by Mindfulness Level interaction were not significant, $F(1,35)=.68, p=.41, p \eta^{2}=.02$, and $F(1,35)=.05, p=.82$, $p \eta^{2}=.00$, respectively.

Relations between Cardiovascular Reactivity to Sensory Intake and Rejection Tasks and the Five

\section{Mindfulness Factors}

As stated in the Introduction, it has been argued that the five factors associated with the construct of mindfulness may be linked to distinct physiological profiles. To examine this possibility, partial correlations were calculated between each cardiovascular measure and each factor score from the KIMS, controlling for resting levels of that parameter. Partial correlations for the sensory intake and sensory rejection tasks are depicted in Tables 3 and 4, respectively. Results showed significant positive correlations between the Act with Awareness factor and all 
three parameters of blood pressure reactivity (SBP, DBP, MAP), but only for the sensory intake task (See Tables 3 and 4).

\section{Task Performance: Mediator between Mindfulness and Reactivity to Sensory Intake?}

As described in the results section above (Task Performance), participants in the high mindfulness group showed faster reaction times and completed more trials during the sensory intake task when compared to the low mindfulness group. It is interesting to note that increased blood pressure reactivity during this task was related to the Act with Awareness factor of mindfulness. To examine whether the relation between Act with Awareness and SBP reactivity could be explained (i.e., mediated) by task performance, these variables were analyzed using a series of linear regressions using the method outlined by Baron and Kenny (1986). First, to demonstrate that the independent variable predicted the dependent variable, FFMQ Act with Awareness score was entered into a regression predicting SBP reactivity to the reaction time task controlling for resting SBP. Results showed that Act with Awareness significantly predicted SBP reactivity to the $\mathrm{RT}$ task, $\beta=.23, t(35)=2.56, p<.05$. Next, to demonstrate that the potential mediator was related to the dependent variable, RT task performance (reaction time in seconds) was entered into a regression as s predictor of SBP reactivity to the RT task, again controlling for resting SBP. Results showed that reaction time (sec.) was not a significant predictor of SBP reactivity to the RT task, $\beta=-.03, t(35)=-.48, p=.64$. To determine if the second measure of RT task performance (number of RT trials completed) was a mediator of this relationship, this analysis was repeated with number of completed RT trials as a predictor. Results showed that number of RT trials completed was also not a significant predictor of SBP reactivity to the RT task, $\beta=03, t(35)=.39, p=.70$. Therefore, these results imply that task performance did not 
mediate the relation between FFMQ Act with Awareness score and SBP reactivity during the RT task.

\section{Discussion}

Results of the present study lend partial support to study hypotheses, extend past research to include novel parameters, and contribute new findings for future study. A main goal of this research was to investigate the stress responses of persons varying in levels of mindfulness by using classic tasks that have been shown to result in fractionation of autonomic responses (sensory intake and sensory rejection tasks; Lacey et al., 1963; Lacey \& Lacey, 1970). Results of the study contrasting overall cardiovascular responses to sensory intake and sensory rejection tasks will be discussed first followed by findings relating to mindfulness.

\section{Sensory Intake and Rejection Task Differentiation}

Task analyses showed significant task differences in cardiovascular reactivity to sensory intake and sensory rejection tasks. Specifically, on nearly every cardiovascular parameter, results showed arousal from rest for the sensory rejection task (mental arithmetic) and the opposite or no change from rest for the sensory intake task (reaction time). Heart rate, blood pressure, and several heart rate variability parameters demonstrated this effect. All of these results lend support to the same general physiological result, though some parameters (e.g., heart rate and blood pressure) increased during the sensory rejection task and decreased during the sensory intake task, whereas others (e.g., HF HRV) showed the opposite trend.

These results replicate and extend historical research investigating directional fractionation of response (Lacey et al., 1963). Lacey and colleagues reported that this fractionation occurred primarily during sensory intake tasks. That is, some measures of autonomic reactivity to the task increased, whereas other decreased. During sensory rejection 
tasks, fractionation was not present, and all measures of autonomic reactivity were aligned. The results of the present study lent support to this perspective in that reactivity to the sensory intake tasks was mild. Additionally, much larger reactivity to sensory rejection tasks on all parameters measured in the current study indicated that no fractionation occurred during these tasks. In summary, the sensory rejection task resulted in clear, and presumably universal, arousal of the autonomic nervous system. Data collected during the sensory intake task, however, showed a more diverse or marginal ANS response.

The present results were congruent with the work of Williams and colleagues (1975), who reported significant task differences in blood pressure and other parameters of cardiovascular reactivity, with the exception of heart rate. These authors reported that all measurements decreased during sensory intake and increased during sensory rejection tasks. During mixed tasks, physiological parameters fell between those resulting from either task. The results of the present study are consistent with these findings related to sensory intake and rejection tasks; however, no mixed tasks were utilized in this study, making replication of their results incomplete.

When replicating historical research, it is important to illuminate differences in measurement apparatus and parameters measured now compared with those used in the original research (40 years ago). Specifically, equipment available to Lacey and colleagues for the measurement of heart rate was less sophisticated than the equipment currently in use for physiological data collection. For this reason, interbeat interval data were not available to be examined for obtaining measures of HRV. In fact, heart rate variability has only emerged as a common measure of stress reactivity recently. Therefore, there is no precedent for examining reactivity to sensory intake or sensory rejection tasks using HRV parameters. 
The extension of this research to heart rate variability is important for explaining the physiological origins of the task differences reported by Lacey and colleagues. HRV is useful in the study of the mechanisms of the autonomic nervous system in that changes in levels of different HRV parameters (e.g., high frequency HRV) indicate changes in the activation of the parasympathetic (PNS) and sympathetic nervous systems (SNS). The PNS and SNS are independent systems that comprise autonomic response to stress. Using typical measures of autonomic activity (e.g., increases in heart rate) it is impossible to determine whether increased autonomic arousal is due to increased activity of the SNS or decreased activity of the PNS. Therefore, HRV is useful for explaining the mechanisms through which autonomic changes take place.

In the present study, we observed an overall increase in heart rate during sensory rejection and a reduction in heart during sensory intake. However, this difference in heart rate response could be caused by either increased activation of the SNS or decreased activation of the PNS during sensory rejection or decreased activation of the SNS or increased activation of the PNS during sensory intake. Analyses of parameters of HRV help elucidate the respective roles of SNS and PNS underlying these heart rate changes. In the present study, the proportion of low frequency HRV increased during the sensory rejection task, as heart rate and other parameters increased, an observation not seen with high frequency HRV. Because HF HRV is an indicator of parasympathetic activity, and LF HRV includes both SNS and PNS influences, it appears as though the heart rate response observed during sensory rejection can be attributed to increased SNS activation. Additionally, LF HRV is thought to be a measure of the delay in baroreceptor responsiveness. Therefore, increases in LF HRV may also indicate less delay in the baroreceptor loop during the sensory rejection task. 
In contrast, the opposite pattern of results was observed for the sensory intake task, that is, HF HRV increased with very little change in LF HRV. Thus, the results of this study indicate that heart rate response observed during the sensory intake task could be attributed to increased activation of the PNS. The PNS is responsible for re-establishing homeostasis following stress and maintaining normal resting functioning (e.g., digestion). Therefore, it follows that percent HF HRV would decrease during a task that was rated as more subjectively stressful. In fact, this mirrors the increase in LF HRV reported above. Additionally, an increase in HF HRV during the sensory intake task was expected, especially when considering the lower subjective stress rating reported for this task. The findings of this study show that fractionation of heart rate responses commonly observed to these two tasks are likely caused by distinct SNS (sensory rejection) and PNS (sensory intake) influences.

Mindfulness and Cardiovascular Reactivity to Sensory Rejection and Sensory Intake

It was hypothesized that individuals high in dispositional mindfulness would show less heart rate acceleration during the sensory rejection task and greater reductions in heart rate during the sensory intake task. Results of heart rate analyses, however, failed to confirm this hypothesis. As a potential explanation for these non-significant results, we refer to the work of Ditto and colleagues (2006), who reported both increased RSA and PEP in response to a body scan meditation, a task utilized in mindfulness training. This result is interesting in that it indicates increases in both PNS and SNS activity during the meditation. This might indicate that mindfulness training could result in increased sympathetic and parasympathetic responses, thus resulting in a lack of significant heart rate change in response to stressful task presentations.

Given that mindfulness meditation includes features similar to sensory intake, one would hypothesize that persons high in self-reported mindfulness would show similar responses to the 
responses of people performing a sensory intake task. For this reason, heart rate variability main effects for mindfulness group were hypothesized. However, results showed no significant difference in HRV across mindfulness levels. Telles and colleagues reported trends toward increased high frequency and decreased low frequency HRV during a 30 minute vipassana (mindfulness) meditation task (Telles, Mohapatra, \& Naveen, 2005). Therefore, one might hypothesize that perhaps mindfulness only has effects on HRV during active meditation, rather than daily activity or during stressful tasks. This result may lend support for daily, purposeful mindfulness meditation practice as a means of influencing the HRV spectrum, and thus altering long-term health outcomes. However, because this is the only study to date examining HRV response to stress among persons differing in mindfulness, additional research is likely necessary before drawing any firm conclusions.

\section{Mindfulness and Blood Pressure}

Though no hypotheses were made in relation to blood pressure, we conducted analyses to investigate the relative effects of task and mindfulness level on this cardiovascular parameter. In addition to the task effect (reported above), there was a main effect of mindfulness on systolic blood pressure reactivity across all tasks. Examination of the means showed that participants with high mindfulness showed greater SBP reactivity to both tasks compared to those low in mindfulness. This finding is the opposite of what would be hypothesized based on recent research (Creswell et al., 2007; Gianaros et al., 2008). Creswell and colleagues (2007) showed that mindfulness (measured with the MAAS, the same measure utilized in this study) was associated with increased responses in the prefrontal cortex and decreased amygdalar responses during an affect labeling task. Gianaros (2008) linked amygdalar activation to blood pressure reactivity via the pons. Hence, it would make sense, based on this research, that mindfulness 
would be linked with less blood pressure reactivity, potentially via pre-frontal cortical control of the amygdala. A few methodological differences between the Creswell study and the present study may explain the observed difference between studies. First, Creswell and colleagues included persons along the full continuum of mindfulness, and performed a median split before comparing groups. With the hopes of capturing the groups at the extreme ends of mindfulness, a tripartite split was employed in the present study. This may indicate that these two samples differed slightly in their self-reported levels of mindfulness. Unfortunately, it is impossible to determine if this is true, as Creswell and colleagues did not report mean MAAS scores for their sample. Additionally, there is another important difference to note between the study by Creswell and colleagues (2007) and the present study. In Creswell's study, participants completed an affect labeling task on a computer while fMRI scans were taken. This task would likely be categorized as a sensory intake task based on the task dichotomy described by Lacey and Lacey (1970). Our procedure differed in that it involved both a sensory intake task and a sensory rejection task. Only hypotheses related to the sensory intake task could be derived from the work of Creswell (2007). Since no studies to date have examined the relation between mindfulness and cardiovascular reactivity to sensory rejection tasks, there was no solid research base to predict the direction of this relation with confidence.

One potential explanation for the increased reactivity observed in SBP is that individuals higher in mindfulness may react more to different environmental stimuli than persons low in mindfulness. Mindfulness is defined as purposeful awareness of the present moment, not a state of relaxation. It is possible that individuals higher in mindfulness show greater reactivity to tasks because they are mindfully attending to the task at hand that requires greater attention (e.g., mental arithmetic; reaction time tasks), and may be able to maintain attention on the task better 
than persons low in mindfulness. To examine this possibility further, it was important to consider whether task performance differed among persons high and low in mindfulness.

\section{Task Performance}

During the sensory intake task, participants in the high mindfulness group showed faster reaction times and completed more trials than participants in the low mindfulness group. This finding makes sense based on previous research findings that show people who practice mindfulness meditation display superior performance on attention tasks involving unexpected stimuli (e.g., Valentine \& Sweet, 1999). Since the timing of presentation of stimuli in the reaction time task varied, these stimuli could be considered unexpected. Conversely, there were no significant differences in task performance during the sensory rejection task (mental arithmetic). Therefore, the results of the present study imply that persons who were higher in dispositional mindfulness performed better on a task requiring sustained attention to an external stimulus, but not in response to a task involving the rejection of these external stimuli.

\section{Mindfulness Factors and Reactivity to Tasks}

We conducted a further examination of the relations between cardiovascular reactivity to the two tasks and the five facets of mindfulness (Observe, Describe, Act with Awareness, Accept without Judgment, Nonreactivity to Inner Experience). Results showed a consistent positive relation between the Act with Awareness factor and blood pressure reactivity during the sensory intake task. The Act with Awareness scale has been described as “engaging fully in one's current activity with undivided attention, or focusing with awareness on one thing at a time" (p. 193; Baer, Smith, \& Allen, 2004). Items included on the Act with Awareness scale reference attention to the present moment, how often a person acts on automatic pilot, and distractibility (Baer et al., 2006). It makes sense that persons scoring high on this scale showed greater blood pressure 
reactions the sensory intake task. This task required attention to the computer monitor for five minutes while waiting for stimuli to appear at random intervals. This task is somewhat tedious, and therefore attention maintenance is critical in task performance. It is interesting to note, however, that task performance (measured by reaction time as well as number of trial completed) was not related to blood pressure reactivity to this task. Hence, it may be the case that persons who report higher awareness of the present moment and who do not often act on autopilot show increased blood pressure reactivity to this task without showing related gains in task performance.

\section{Limitations}

The present study has several limitations. First, we utilized a limited sample of undergraduate students enrolled in Psychology courses at West Virginia University. For this reason, the sample age was relatively young (approximately 19 years), and results may not generalize to other age groups or persons without a college education. Additionally, our sample consisted of primarily women (approximately 70\%). Therefore, it was not possible to compare men and women on outcome measures. Finally, the sample was primarily Caucasian, with other racial groups represented by one person or unrepresented, making it difficult to gauge the generalizability of the reported results to other racial groups.

The study is also somewhat limited in its measurement of heart rate variability. Though we utilized five-minute tasks and rest periods, HRV has been shown to vary over 24-hours. However, we did not use any HRV measures intended to measure this daily change in HRV (e.g., SDNN). Therefore, the HRV results reported above may not generalize to these parameters. Despite this limitation, other studies have conducted analyses of HRV across time intervals comparable to the 5-min lengths used in this study (e.g., Berntson et al., 1997). 
The present study may also be limited in its measurement of mindfulness. Though some authors argue that mindfulness is a naturally-occurring trait (e.g., Brown \& Ryan, 2003), selfreport measures of mindfulness may not be the most valid measures of mindfulness. Until recently, some investigators interested in mindfulness were of the opinion that no valid selfreport measure of mindfulness existed (e.g., Dimidjian \& Linehan, 2003). However, with the development of the MAAS and the FFMQ (Baer et al., 2006; Brown \& Ryan, 2003), it is more likely that we are collecting valid self-report measurements of mindfulness. Other investigators emphasize the importance of distinguishing between dispositional, naturally-occurring mindfulness and the awareness that develops through deliberate mindfulness meditation (e.g., Kabat-Zinn, 1990).

It is important to note that, though scores on the MAAS (the selection measure in the present study) have been shown to change with mindfulness training, the MAAS may only be measuring one facet of mindfulness. Specifically, research by Baer and colleagues (2006) showed that mindfulness is comprised of five facets that are measured by a variety of self-report questions. When these investigators reported the results of a factor analysis of these measures (the FFMQ), the MAAS loaded solely on one factor: the Act with Awareness scale. For this reason, it may be the case that the MAAS is primarily a measure of acting with awareness, only one facet of mindfulness. Thus, participants in the present study may have been screened based on their Act with Awareness score rather than overall mindfulness.

One final limitation of the present study becomes clear when examining the face validity of mindfulness measures. This study did not include a measure of social desirability. Therefore, there is no way to determine if participants are simply responding to questions with what they think of as the correct response. This is especially relevant when considering measures of 
mindfulness. Though these questions don't have a "right or wrong" answer, and participants are informed of this, it is possible that participants responded with the answer they thought researchers wanted, or the response that would make them "look good." Future research utilizing self-report measures of mindfulness should incorporate a measure of social desirability to control for this possibility.

\section{Future Directions}

Future research seeking to investigate autonomic response to tasks and the role of mindfulness in ANS reactivity should address several areas. Specifically, the results of this study attempt to clarify the role of the PNS and SNS in differential response to tasks. However, these results may differ in populations with different demographic characteristics, specifically, age, sex, race, and education level. Future research should address potential differences based on these demographics. Research investigating the role of mindfulness in cardiovascular reactivity to stress should address the potential concurrent activation of the SNS and PNS in response to different tasks. Additionally, it would be interesting to assess changes in reactivity to stress before and after formal mindfulness meditation training to determine whether comparable influences are observed when mindfulness is measured in this way.

It is important to consider implications of these findings for clinical practice. Although the current study did not involve training in mindfulness, findings regarding task performance and SBP reactivity may be important to consider when working with individuals whose occupations involve sensory intake. For example, persons who are required to attend to a stimulus for long periods of time and detect unexpected or irregular stimuli (e.g., air traffic controllers) may benefit from mindfulness training to increase performance during work-related activity. Additionally, because individuals high in mindfulness may show better performance on 
sensory intake tasks, these tasks may be useful clinical tools. Specifically, if a mindfulness-based intervention (e.g., MBSR) is effective in increasing mindfulness levels, participants could show improvement on sensory intake task performance following a mindfulness training protocol.

Mindfulness continues to be an important clinical tool, whether observed dispositionally or taught via interventions like MBSR. Learning about its effects, particularly those involving autonomic and central nervous system activity, will help explain the mechanisms underlying the salubrious effects associated with mindfulness. Through additional research in this area, interventions of this sort may continue to evolve into mainstream practice within clinical health psychology. 


\section{References}

Achenbach, T. M. (1991). Manual for the Child Behavior Checklist: Ages 4-18 and 1991 profile. University of Vermont, Department of Psychiatry, Burlington, VT.

Aron, A. R., Robbins, T. W., \& Poldrack, R. A. (2004). Inhibition and the right inferior frontal cortex. Trends in Cognitive Sciences, 8, 170-177.

Baer, R. A., Smith, G. T., \& Allen, K. B. (2004). Assessment of mindfulness by self-report: The Kentucky Inventory of Mindfulness Skills. Assessment, 11, 191-206.

Baer, R. A., Smith, G. T., Hopkins, J., Krietemeyer, J, \& Toney, L. (2006). Using self-report assessment methods to explore facets of mindfulness. Assessment, 13, 27-45.

Baron, R. M. \& Kenny, D. A. (1986). The moderator-mediator variable distinction in social psychological research: Conceptual, strategic, and statistical considerations. Journal of Personality and Social Psychology, 51, 1173-1182.

Beck, A. T., Rush, A. J., Shaw, B. F., \& Emery, G. (1979). Cognitive therapy of depression. New York: Guilford Press.

Berntson, G. G., Bigger, J. T., Eckberg, D. L., Grossman, P., Kaufmann, P. G., Malik, M., Nagaraja, H. N., et al. (1997). Heart rate variability: Origins, methods, and interpretive caveats. Psychophysiology, 34, 623-648.

Bishop S. R.., Lao, M., Shapiro, S., Carlson, L., Anderson, N. D., Carmondy, J., Segal, Z. V., Abbey, S., Speca, M., Velting, D., \& Devins, G. (2004). Mindfulness: A proposed operational definition. Clinical Psychology: Science and Practice, 11, 230-241.

Blumenthal, J.A., Sherwood, A., Gullete, E.C.D., Georgiades, A., Tweedy, D. (2002). Behavioral approaches to the treatment of essential hypertension. Journal of Counseling and Clinical Psychology, 70, 569-589. 
Brown, K. W., \& Ryan, R. M. (2003). The benefits of being present: mindfulness and its role in psychological well-being. Journal of Personality and Social Psychology, 84, 822-48.

Creswell, D. J., Way, B. M., Eisenberger, N. I., \& Lieberman, M. D. (2007). Neural Correlates of Dispositional Mindfulness During Affect Labeling. Psychosomatic Medicine, 69, 560565.

Creswell, D. J., Eisenberger, N. I., Taylor, S. E., \& Seeman, T. E. (2008). Neural and behavioral correlates of dispositional mindfulness during stress. Paper presented at the $66^{\text {th }}$ Annual Scientific Meeting of the American Psychosomatic Society, Baltimore, MD.

Ditto, B., Eclache, M., \& Goldman, N. (2006). Short-term autonomic and cardiovascular effects of mindfulness body scan meditation. Annals of Behavioral Medicine, 32, 227-234.

Gianaros, P. J., Sheu, L. K., Matthews, K. A., Jennings, J. R., Manuck, S. B., \& Hariri, A. R. (2008). Individual differences in stressor-evoked blood pressure reactivity vary with activation, volume, and functional connectivity of the amygdale. The Journal of Neuroscience, 28, 990-999.

Hayes, S.C., Luoma, J.B., Bond, F.W., Masuda, A. \& Lillis, J. (2006). Acceptance and Commitment Therapy: Model, processes and outcomes. Behaviour Research and Therapy, 44, 1-25.

Kabat-Zinn, J. (1990). Full catastrophe living: The program of the Stress Reduction Clinic at the University of Massachusetts Medical Center. New York: Dell Publishing.

Kabat-Zinn, J., Lipworth, L., \& Burney, R. (1985). The clinical use of mindfulness meditation for the self-regulation of chronic pain. Journal of Behavioral Medicine, 8, 163-190.

Kabat-Zinn, J., Massion, A. O., Kristeller, J., Peterson, L. G., Fletcher, K. E., Pbert, L., Lenderking, W. R, \& Santorelli, S. (1992). Effectiveness of a meditation-based stress 
reduction program in the treatment of anxiety disorders. American Journal of Psychiatry, 149, 936-943.

Hayes, S. C., Luoma, J. B., Bond, F. W., Masuda, A., \& Lillis, J. (2006). Acceptance and Commitment Therapy: Model, processes and outcomes. Behaviour Research and Therapy, 44, 1-25.

Kenny, M. A, \& Williams, J. M. G. (2007). Treatment-resistant depressed patients show a good response to Mindfulness-based Cognitive Therapy. Behaviour Research and Therapy, 45, 617-625.

Lacey, J. I., Kagan, J., Lacey, B. C., \& Moss, H. (1963). The Visceral Level: Situational determinants and behavioral correlates of autonomic response patterns. In P. H. Knapp (Ed.) Expressions of the Emotions in Man (p. 161-198). New York: International Universities Press.

Lacey, J. I., \& Lacey, B. C. (1970). Some autonomic-central nervous system interrelationships. In P. Black (Ed.) Physiological Correlates of Emotion (pp. 205-227). New York: Academic Press.

Linehan, M. M. (1993) Cognitive-Behavioral Treatment for Borderline Personality Disorder. New York: Guilford.

Ma, S. H., \& Teasdale, J. D. (2004). Mindfulness-based cognitive therapy for depression: replication and exploration of differential relapse prevention effects. Journal of Counseling and Clinical Psychology, 72, 31-40.

Marler, M. R., Jacob, R. G., Lehoszky, J.P., \& Shapiro, A. P. (1988). The statistical analysis of treatment effects in 24-hour ambulatory blood pressure recordings. Statistics in Medicine, 7, 697-716. 
Morone, N.E., Greco, C.M., \& Weiner, D.K. (2008) Mindfulness meditation for the treatment of chronic low back pain in older adults: A randomized controlled pilot study. Pain, 134, 310-319.

Niskanen, J., Tarvainen, M.P., Ranta-aho, P.O., \& Karjalainen, P.A. (2002). Software for advances HRV analysis. Submitted to Computer Methods and Programs in Biomedicine.

Nolen-Hoeksema, S., Stice, E., Wade, E. \& Bohon, C. (2007). Reciprocal relations between rumination and bulimc, substance abuse, and depressive symptoms in female adolescents. Journal of Abnormal Psychology, 116, 198-207.

Nyklicek, I. \& Kuijpers, K. F. (2008). Effects of Mindfulness-Based Stress Reduction intervention on psychological well-being and quality of life: Is increased mindfulness indeed the mechanism? Annals of Behavioral Medicine, 35, 331-340.

Ochsner, K. N., Binge, S. A., Gross, J. J. \& Gabrieli, J. D. E. (2002). Rethinking Feelings: An fMRI study of the cognitive regulation of emotion. Journal of Cognitive Neuroscience, $14,1215-1229$.

Ramel, W., Goldin, P. R., Carmona, P. E., \& McQuaid, J. R. (2004). The effects of mindfulness meditation on cognitive processes and affect in patients with past depression. Cognitive Therapy and Research, 28, 433-455.

Segal, Z. V., Williams, J. M. G., \& Teasdale, J. D. (2002). Mindfulness-based cognitive therapy for depression-A new approach to preventing relapse. New York: Guilford Press.

Semple, R. J., Reid, E. F. G, \& Miller, L. (2005). Treating anxiety with mindfulness: an open trial of mindfulness training for anxious children. Journal of Cognitive Psychotherapy: An International Quarterly, 19, 379-392.

Siegel, D. J. (2007). The mindful brain. New York: Norton. 
Skinner, B. F. (1976). About Behaviorism. New York: Vintage.

Tabachnick, B. G., \& Fidell, L. S. (2001). Using multivariate statistics: 4th edition. Needham Heights, MA: Allyn \& Bacon.

Telles, S., Mohapatra, R.S. \& Naveen, K.V. (2005). Heart rate variability spectrum during vipassana mindfulness meditation. Journal of Indian Psychology, 23, 1-5.

Valentine, E. R. \& Sweet, P. L. G. (1999). Meditation and attention: A comparison of the effects of concentrative and mindfulness meditation on sustained attention. Mental Health. Religion, \& Culture, 2, 59-70.

Walach, H., Buchheld, N., Buttenmuller, V., Kleinknecht, N., \& Schmidt, S. (2006). Measuring mindfulness-The Freiburg Mindfulness Inventory (FMI). Personality and Individual Differences, 40, 1543-1555.

Williams, M., Teasdale, J., Segal, Z., \& Kabat-Zinn, J. (2007). The mindful way through depression. New York: Guilford Press.

Williams, R. B., Bitker, T. E., Buchsbaum, M. S., \& Wynne, L. C. (1975). Cardiovascular and neurophysiologic effects of sensory intake and rejection. I. Effect of cognitive tasks. Psychophysiology, 12, 427-433. 
Table 1

Means, Standard Deviations, and Results of Mindfulness Level Comparisons

\begin{tabular}{|c|c|c|c|c|}
\hline & $\operatorname{High} M(S D)$ & Low $M(S D)$ & $F$ & $P$ \\
\hline Age (yrs) & $18.90(.79)$ & $19.74(2.13)$ & 2.70 & .12 \\
\hline MAAS Total & $72.05(7.27)$ & $45.53(5.96)$ & 154.30 & .000 \\
\hline FFMQ Total & $138.65(14.60)$ & $113.26(13.52)$ & 31.65 & .000 \\
\hline FFMQ ActAware & $35.10(4.56)$ & $22.00(2.87)$ & 113.77 & .000 \\
\hline FFMQ Describe & $28.10(7.29)$ & $22.74(5.68)$ & 6.52 & .02 \\
\hline FFMQ Nonjudge & $29.70(4.44)$ & $26.68(5.80)$ & 3.35 & .08 \\
\hline FFMQ Nonreact & $18.50(3.43)$ & $16.79(4.12)$ & 2.00 & .17 \\
\hline FFMQ Observe & $27.25(5.93)$ & $25.05(5.09)$ & 1.53 & .22 \\
\hline $\mathrm{SBP}(\mathrm{mm} \mathrm{Hg})$ & $114.46(9.81)$ & $118.97(12.48)$ & 1.55 & .22 \\
\hline DBP (mm Hg) & $63.14(11.55)$ & $65.33(9.28)$ & .41 & .52 \\
\hline MAP (mm Hg) & $80.24(8.98)$ & $83.21(6.21)$ & 1.37 & .25 \\
\hline HR (bpm) & $77.14(10.92)$ & $77.65(9.05)$ & .03 & .88 \\
\hline $\mathrm{RR}(\mathrm{ms})$ & $798.76(127.34)$ & $783.43(86.91)$ & .19 & .67 \\
\hline LF HRV (\%) & $32.51(11.09)$ & 33.53 (11.93) & .08 & .79 \\
\hline HF HRV (\%) & $27.64(16.62)$ & $21.55(13.36)$ & 1.59 & .22 \\
\hline
\end{tabular}

Note. All cardiovascular measures are at rest. Nonreact. is nonreactivity to inner experience; Observe is observing, noticing, attending to sensations, perceptions, thoughts, and feelings; ActAware is acting with awareness, automatic pilot, concentration, nondistraction; Describe is describing, labeling with words; and Nonjudge is nonjudging of experience (Baer et al., 2006). 
Table 2

Descriptive Statistics for Dependent Variables based on Mindfulness Level

\begin{tabular}{lllll}
\hline & MA High $M(S D)$ & MA Low $M(S D)$ & RT High $M(S D)$ & RT Low $M(S D)$ \\
\hline HR (bpm) & $85.42(10.22)$ & $84.85(10.14)$ & $75.32(9.90)$ & $76.90(9.86)$ \\
RR (ms) & $717.36(93.02)$ & $722.51(92.52)$ & $816.08(120.32)$ & $794.03(101.79)$ \\
SBP (mm Hg) & $129.30(14.55)$ & $128.56(14.53)$ & $118.23(10.51)$ & $119.22(11.48)$ \\
DBP (mm Hg) & $72.33(10.27)$ & $74.80(7.49)$ & $69.23(10.26)$ & $68.15(9.00)$ \\
MAP (mm Hg) & $91.31(9.25)$ & $92.72(7.30)$ & $85.57(8.71)$ & $85.17(6.36)$ \\
LF HRV (\%) & $42.77(15.17)$ & $49.70(12.57)$ & $32.58(13.90)$ & $35.18(13.56)$ \\
HF HRV (\%) & $25.62(12.66)$ & $21.39(8.61)$ & $40.63(20.43)$ & $29.14(14.32)$ \\
Reaction Time (sec) & -- & - & $.68(.11)$ & $.90(.43)$ \\
Trials Completed & $34.41(14.90)$ & $37.71(14.55)$ & $54.58(1.92)$ & $52.42(3.53)$ \\
Percent Correct & $71.50(29.29)$ & $76.89(14.13)$ & $96.64(2.23)$ & $91.08(22.43)$ \\
Stress Rating & $2.19(.74)$ & $1.84(.97)$ & $.69(.54)$ & $.59(.97)$ \\
\hline
\end{tabular}

Note. "MA" is mental arithmetic; "RT" is reaction time; "high" is high mindfulness level; "low" is low mindfulness level; "RR" is heart rate in R-R interval. 
Dispositional Mindfulness 50

Table 3

Partial Correlations: Mindfulness Facets and Cardiovascular Reactivity to a Sensory Intake

Task controlling for Resting Measures

\begin{tabular}{llllll}
\hline Cardiovascular Measure & Nonreact. & Observe & ActAware & Describe & Nonjudge \\
\hline HR & -.20 & -.09 & .07 & -.22 & -.13 \\
R-R & .18 & .06 & .03 & .13 & .01 \\
SBP & .25 & .12 & $.40^{*}$ & .30 & .05 \\
DBP & .27 & .13 & $.46^{*}$ & .19 & .13 \\
MAP & .30 & .15 & $.48^{*}$ & .24 & .11 \\
LF HRV & -.08 & -.09 & .06 & .14 & -.09 \\
HF HRV & -.15 & -.15 & -.06 & -.02 & -.23 \\
VLF HRV & .03 & .23 & -.17 & -.12 & .11 \\
RMSSD & .03 & -.03 & -.24 & -.13 & -.13 \\
SDNN & .07 & .05 & -.24 & -.13 & -.10 \\
\hline
\end{tabular}

${ }^{*} p<.01$

Note. Nonreact. is nonreactivity to inner experience; Observe is observing, noticing, attending to sensations, perceptions, thoughts, and feelings; ActAware is acting with awareness, automatic pilot, concentration, nondistraction; Describe is describing, labeling with words; and Nonjudge is nonjudging of experience (Baer et al., 2006). 
Dispositional Mindfulness 51

Table 4

Partial Correlations: Mindfulness Facets and Cardiovascular Reactivity to a Sensory Rejection Task controlling for Resting Measures

\begin{tabular}{llllll}
\hline Cardiovascular Measure & Nonreact. & Observe & ActAware & Describe & Nonjudge \\
\hline HR & -.00 & -.02 & -.09 & .09 & .06 \\
R-R & .07 & .06 & .05 & -.03 & -.06 \\
SBP & .20 & .08 & -.03 & .17 & -.04 \\
DBP & .13 & -.12 & -.14 & -.02 & -.16 \\
MAP & .21 & -.04 & -.12 & .08 & -.13 \\
LF HRV & -.11 & .10 & -.12 & -.23 & .02 \\
HF HRV & .19 & .08 & .13 & .21 & .05 \\
RMSSD & .25 & .11 & .20 & .06 & .06 \\
\hline
\end{tabular}

Note. Nonreact. is nonreactivity to inner experience; Observe is observing, noticing, attending to sensations, perceptions, thoughts, and feelings; ActAware is acting with awareness, automatic pilot, concentration, nondistraction; Describe is describing, labeling with words; and Nonjudge is nonjudging of experience (Baer et al., 2006). 
Dispositional Mindfulness 52

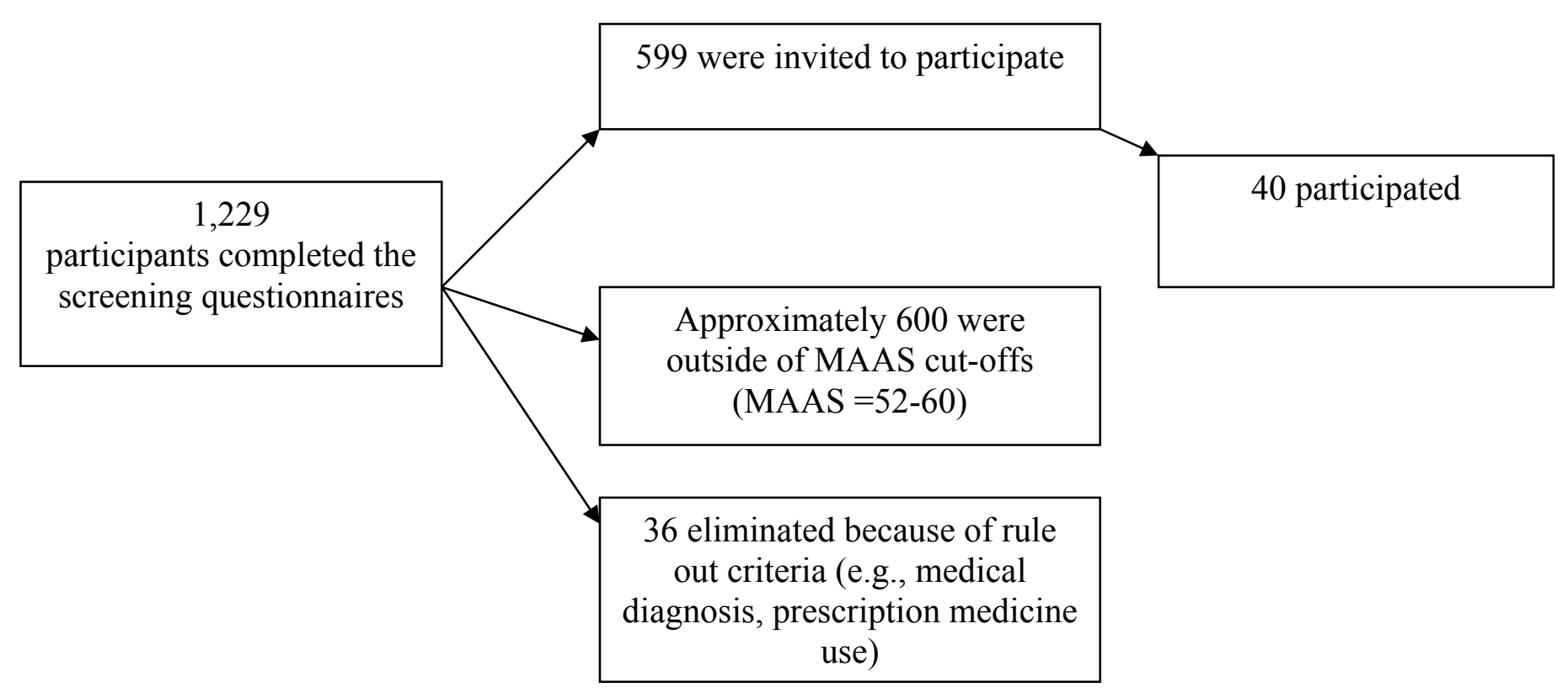

Figure 1. Screening and categorization of participants. 


\section{Appendix A}

Demographics Questionnaire

Participant \#:

Date:

Height(in.):

Weight(lbs):

\section{Your Information:}

Your age

Your sex

o Male

○ Female

Your race

o Black

○ White

$\circ$ Hispanic

o Asian

- Biracial (specify):

$\circ$ Other

Total years of education you have completed:

- High school

- 1 year college

- 2 years college

- 3 years college

- 4 or more years college

Please describe any cardiovascular related illness that you may have, including high blood pressure:

Please list any other medical or psychiatric problems that you have:

Please list any major surgeries and medical, or psychiatric illnesses you have had in the past. 
Females: When did you start your last menstrual cycle?

$\circ$ I am a Male

$\circ$ less than one week ago

$\circ$ one week ago

$\circ$ two weeks ago

$\circ$ three weeks ago

$\circ$ four weeks ago

$\circ$ more than four weeks ago

$\circ$ I am currently pregnant

Females: Are you currently on birth control (contraceptives).

$\circ$ I am a male

$\circ$ No

$\circ$ Yes

What type of birth control are you taking?

Please list any drugs (legal or otherwise) that you are currently taking including; birth control (contraceptives), heart medications, cold or allergy medications, over the counter medications, asthma medications, Beta-Blockers (i.e. Inderal, Tenormin), psychoactive drugs (i.e. Adderall, Xanax, Haldol, Lithium, Prozac), or diet pills.

On average, how often do you smoke cigarettes?

o never

○ I am not currently smoking

$\circ$ less than one pack per day

o 1-2 packs per day

○ 2-3 packs per day

$\circ$ greater than 3 packs per day

On average, how often do you use smokeless tobacco?

o never

$\circ$ I am not currently using smokeless tobacco

- 1-4 times per day

० 5-8 times per day

$\circ$ 9-13 times per day

$\circ$ greater than thirteen times per day

How often do you drink alcohol?

$\circ$ never

$\circ$ infrequently (a few drinks per year)

$\circ$ occasionally (1-2 drinks per month) 
O weekly (1-3 drinks per week)

$\circ$ weekly (3-6 drinks per week)

$\circ$ daily (7-14 drinks per week)

$\circ$ daily (more than 14 drinks per week)

How many cups of caffeinated coffee, tea, or soda do you have per day?

o none

$\circ$ 1-2 cups per day

○ 3-4 cups per day

$\circ 5-6$ cups per day

$\circ$ 7-8 cups per day

$\circ$ greater than eight cups per day

About how many caffeinated beverages do you usually have by this time of day?

How many times per week do you engage in aerobic physical activity?
$\circ$ never
$\circ$ 1-2 times
○ 3-6 times
$\circ 7$ or more times

For how long do you typically exercise on each occasion?

○ 5-10 minutes

○ 10-15 minutes

○ 15-30 minutes

○ 30-60 minutes

$\circ$ more than 60 minutes

How many hours of sleep did you get last night?

$\circ$ Less than 4 hours

$\circ$ 4-5 hours

$\circ$ 5-6 hours

$\circ 6-7$ hours

$\circ 7-8$ hours

० 8-9 hours

$\circ$ greater than 9 hours

\section{Family Information:}

What is your best estimate of your family's total income?

$\circ$ Less than 24,999

○ 25,000 to 34,999

○ 35,000 to 49,999

○ 50,000 to 74,999

○ 75,000 to 99,999

- 100,000 to 149,999

$\circ$ Greater than 150,000 
Approximately how old is your father?

Is he currently living?

$\circ$ yes

$\circ$ no

Did/does your father have high blood pressure (hypertension)?

$\circ$ yes

$\circ$ no

How certain are you that he did, or did not, have high blood pressure (hypertension)?

○ Absolutely (100\%) certain

○ Almost (75\%) certain

$\circ$ Not sure at all $(25 \%)$

$\circ$ No information by which to judge $(0 \%)$

Did/does your father have any heart problems such as angina (chest pains), a heart attack, or coronary heart disease?

o yes

o no

If yes, please specify if you are able:

How certain are you that he did, or did not, have a heart problem as indicated above?

$\circ$ Absolutely $(100 \%)$ certain

○ Almost $(75 \%)$ certain

$\circ$ Not sure at all $(25 \%)$

$\circ$ No information by which to judge $(0 \%)$

Did/does your father have diabetes?

$\circ$ yes

o no

How certain are you that he did, or did not, have diabetes?

$\circ$ Absolutely $(100 \%)$ certain

$\circ$ Almost (75\%) certain

$\circ$ Not sure at all (25\%)

$\circ$ No information by which to judge $(0 \%)$

Did/does your father have a kidney disease (other than kidney stones)?

$\circ$ yes

o no

How certain are you that he did, or did not, have a kidney disease (other than kidney stones)? $\circ$ Absolutely $(100 \%)$ certain 
○ Almost (75\%) certain

$\circ$ Not sure at all $(25 \%)$

$\circ$ No information by which to judge $(0 \%)$

Did/does your father have cancer?

o yes

o no

How certain are you that he did, or did not, have cancer?

$\circ$ Absolutely $(100 \%)$ certain

○ Almost (75\%) certain

$\circ$ Not sure at all $(25 \%)$

○ No information by which to judge $(0 \%)$

If you know, please list what type(s) of cancer he had?

Approximately how old is your mother?

Is she currently living?

o yes

o no

Did/does your mother have high blood pressure (hypertension)?

o yes

o no

How certain are you that she did, or did not, have high blood pressure (hypertension)?

$\circ$ Absolutely $(100 \%)$ certain

○ Almost (75\%) certain

$\circ$ Not sure at all $(25 \%)$

○ No information by which to judge $(0 \%)$

Did/does your mother have any heart problems such as angina (chest pains), a heart attack, or coronary heart disease?

$\circ$ yes

$\circ$ no

If yes, please specify if you are able:

How certain are you that she did, or did not, have a heart problem as indicated above?

○ Absolutely (100\%) certain

○ Almost (75\%) certain

$\circ$ Not sure at all (25\%)

○ No information by which to judge $(0 \%)$ 
Did/does your mother have diabetes?

$\circ$ yes

$\circ$ no

How certain are you that she did, or did not, have diabetes?

$\circ$ Absolutely $(100 \%)$ certain

○ Almost $(75 \%)$ certain

$\circ$ Not sure at all (25\%)

$\circ$ No information by which to judge $(0 \%)$

Did/does your mother have a kidney disease (other than kidney stones)?

$\circ$ yes

o no

How certain are you that she did, or did not, have a kidney disease (other than kidney stones)?

○ Absolutely (100\%) certain

$\circ$ Almost (75\%) certain

$\circ$ Not sure at all (25\%)

○ No information by which to judge $(0 \%)$

Did/does your mother have cancer?

$\circ$ yes

o no

How certain are you that she did, or did not, have cancer?

○ Absolutely (100\%) certain

○ Almost (75\%) certain

$\circ$ Not sure at all $(25 \%)$

$\circ$ No information by which to judge $(0 \%)$

If you know, please list what type(s) of cancer she had? 


\section{Appendix B}

\section{MAAS}

Below is a collection of statements about your everyday experience. Using the 1-6 scale below, please indicate how frequently or infrequently you currently have each experience. Please answer according to what really reflects your experience rather than what you think your experience should be.

$\mathbf{1}=$ almost always, $\mathbf{2}=$ very frequently, $\mathbf{3}=$ somewhat frequently, $\mathbf{4}=$ somewhat infrequently, $\mathbf{5}=$ very infrequently, and $\mathbf{6}=$ almost never

1. I could be experiencing some emotion and not be conscious of it until some time later.

2. I break or spill things because of carelessness, not paying attention, or thinking of something else.

3. I find it difficult to stay focused on what's happening in the present.

4. I tend to walk quickly to get where I'm going without paying attention to what I experience along the way.

5. I tend not to notice feelings of physical tension or discomfort until they really grab my attention.

6. I forget a person's name almost as soon as I've been told it for the first time.

7. It seems I am "running on automatic" without much awareness of what I'm doing.

8. I rush through activities without being really attentive to them.

9. I get so focused on the goal I want to achieve that I lose touch with what I am doing right now to get there.

10. I do jobs or tasks automatically, without being aware of what I'm doing.

11. I find myself listening to someone with one ear, doing something else at the same time.

12. I drive places on "automatic pilot" and then wonder why I went there.

13. I find myself preoccupied with the future or the past.

14. I find myself doing things without paying attention.

15. I snack without being aware that I'm eating. 
Appendix C

\section{FFMQ}

\section{Factor 1: Nonreactivity to Inner Experience}

FMI 18: I perceive my feelings and emotions without having to react to them.

FMI 25: I watch my feelings without getting lost in them.

FMI 26: In difficult situations, I can pause without immediately reacting.

MQ 1: When I have distressing thoughts or images, I am able just to notice them without reacting.

MQ 4: When I have distressing thoughts or images, I feel calm soon after.

MQ 9: When I have distressing thoughts or images, I "step back" and am aware of the thought or image without getting taken over by it.

\section{Factor 2: Observing/noticing/attending to sensations/perceptions/thoughts/feelings}

KIMS 9: When I'm walking, I deliberately notice the sensations of my body moving.

KIMS 13: When I take a shower or a bath, I stay alert to the sensations of water on my body.

KIMS 17: I notice how foods and drinks affect my thoughts, bodily sensations, and emotions.

KIMS 21: I pay attention to sensations, such as the wind in my hair or sun on my face.

KIMS 25: I pay attention to sounds, such as clocks ticking, birds chirping, or cars passing.

KIMS 29: I notice the smells and aromas of things.

KIMS 33: I notice visual elements in art or nature, such as colors, shapes, textures, or patterns of light and shadow.

KIMS 37: I pay attention to how my emotions affect my thoughts and behavior.

\section{Factor 3: Acting with awareness/automatic pilot/concentration/nondistraction}

MAAS 3: I find it difficult to stay focused on what's happening in the present.

MAAS 7: It seems I am "running on automatic" without much awareness of what I'm doing.

MAAS 8: I rush through activities without being really attentive to them.

MAAS 10: I do jobs or tasks automatically, without being aware of what I'm doing.

MAAS 14: I find myself doing things without paying attention.

KIMS 3: When I do things, my mind wanders off and I'm easily distracted.

KIMS 23: I don't pay attention to what I'm doing because I'm daydreaming, worrying, or otherwise distracted.

CAMS 6: I am easily distracted.

\section{Factor 4: Describing/labeling with words}

KIMS 2: I'm good at finding the words to describe my feelings.

KIMS 6: I can easily put my beliefs, opinions and expectations into words.

KIMS 14: It's hard for me to find the words to describe what I'm thinking.

KIMS 18: I have trouble thinking of the right words to express how I feel about things. 
KIMS 22: When I have a sensation in my body, it's difficult for me to describe it because I can't find the right words.

KIMS 26: Even when I'm feeling terribly upset, I can find a way to put it into words.

KIMS 34: My natural tendency is to put my experiences into words.

CAMS 5: I can usually describe how I feel at the moment in considerable detail.

\section{Factor 5: Nonjudging of experience}

KIMS 4: I criticize myself for having irrational or inappropriate emotions

KIMS 12: I tell myself that I shouldn't be feeling the way I'm feeling.

KIMS 16: I believe some of my thoughts are abnormal or bad and I shouldn't think that way.

KIMS 20: I make judgments about whether my thoughts are good or bad

KIMS 28: I tell myself that I shouldn't be thinking the way I'm thinking.

KIMS 32: I think some of my emotions are bad or inappropriate and I shouldn't feel them.

KIMS 36: I disapprove of myself when I have irrational ideas.

MQ 8: When I have distressing thoughts or images, I judge myself as good or bad, depending what the thought/image is about. 


\section{Appendix D}

\section{Sensory Intake Task Instructions}

1. Please enter your SONA systems identification number into the space provided.

2. On the next screen, you will see a focus point. Keep your eyes on the middle of the focus point. Next, a symbol will appear on the screen. Your task is to determine whether the symbol is a letter or a number. If it is a letter, press the " $\mathrm{L}$ " key. If it is a number, press the "N" key. Respond as quickly as you can, and continue responding until the task is complete.

3. When you have read these instructions, check the box indicating that you have completed the instructions and know what to do. Then click the button labeled "OK." 


\section{Appendix E}

Order Effects Analyses for Heart Rate (bpm)

Tests of Between Subject Effects

\begin{tabular}{lllll}
\hline SS & DF & MS & F & $P$
\end{tabular}

Source of Variation

\begin{tabular}{lllllll}
\hline Within Cells & 1171.81 & 35 & 33.48 & & & \\
Regression & 5708.96 & 1 & 5708.96 & 170.52 & .000 \\
Task Order & 3.04 & 1 & 3.04 & .09 & .765 \\
\hline
\end{tabular}

Tests of Within Subjects Effects

\begin{tabular}{lllll}
\hline SS & DF & MS & F & $p$
\end{tabular}

Source of Variation

Within Cells

$360.96 \quad 35 \quad 10.31$

Regression

.72

$1 \quad .72$

.07

.793

Task

1532.99

Task Order BY Task

.37

1

1532.99

$148.64 \quad .000$

.37

$1 \quad .37$

.04

.852 
Order Effects Analyses for Heart Rate (R-R interval)

\begin{tabular}{llllll}
\hline Tests of Between Subject Effects & \multicolumn{6}{c}{} \\
\cline { 2 - 6 } & \multicolumn{7}{c}{ SS } & DF & MS & F & $p$ \\
\cline { 2 - 6 } Source of Variation & & & & & \\
\hline Within Cells & 129735.05 & 35 & 3815.74 & & \\
Regression & 600704.46 & 1 & 600704.46 & 157.43 & .000 \\
Task Order & 320.82 & 1 & 320.82 & .08 & .774 \\
\hline
\end{tabular}

\begin{tabular}{|c|c|c|c|c|c|}
\hline \multirow[t]{2}{*}{ Tests of Within Subjects Effects } & & & & & \multirow[b]{2}{*}{$p$} \\
\hline & SS & DF & MS & $\mathrm{F}$ & \\
\hline \multicolumn{6}{|l|}{ Source of Variation } \\
\hline Within Cells & 40467.05 & 35 & 1190.21 & & \\
\hline Regression & 192.38 & 1 & 192.38 & .16 & .690 \\
\hline Task & 116837.27 & 1 & 116837.27 & 98.17 & .000 \\
\hline Task Order BY Task & 124.94 & 1 & 124.94 & .10 & .748 \\
\hline
\end{tabular}


Order Effects Analyses for Systolic Blood Pressure

Tests of Between Subject Effects

\begin{tabular}{lllll}
\hline SS & DF & MS & F & $P$
\end{tabular}

Source of Variation

\begin{tabular}{llllll}
\hline Within Cells & 1517.33 & 35 & 44.63 & & \\
Regression & 8659.24 & 1 & 8659.24 & 194.03 & .000 \\
Task Order & 54.61 & 1 & 54.61 & 1.22 & .276 \\
\hline
\end{tabular}

Tests of Within Subjects Effects

\begin{tabular}{lllll}
\hline SS & DF & MS & F & $p$
\end{tabular}

Source of Variation

\begin{tabular}{llllll}
\hline Within Cells & 906.69 & 35 & 26.67 & & \\
Regression & 7.22 & 1 & 7.22 & .27 & .606 \\
Task & 1569.70 & 1 & 1569.70 & 58.86 & .000 \\
Task Order BY Task & 73.19 & 1 & 73.19 & 2.74 & .107 \\
\hline
\end{tabular}


Order Effects Analyses for Diastolic Blood Pressure

\begin{tabular}{lllllll}
\hline Tests of Between Subject Effects & \multicolumn{6}{c}{} \\
\cline { 2 - 7 } & SS & DF & MS & F & $P$ \\
\cline { 2 - 7 } Source of Variation & & & & & \\
\hline Within Cells & 1622.39 & 35 & 47.72 & & \\
Regression & 3643.15 & 1 & 3643.15 & 76.35 & .000 \\
Task Order & 81.51 & 1 & 81.51 & 1.71 & .200 \\
\hline
\end{tabular}

\begin{tabular}{llllll}
\hline Tests of Within Subjects Effects & \multicolumn{7}{c}{} \\
\cline { 2 - 7 } & SS & DF & MS & F & $p$ \\
\cline { 2 - 7 } Source of Variation & & & & & \\
\hline Within Cells & 1025.36 & 35 & 30.16 & & \\
Regression & 11.57 & 1 & 11.57 & .38 & .540 \\
Task & 413.75 & 1 & 413.75 & 13.72 & .001 \\
Task Order BY Task & .03 & 1 & .03 & .00 & .975 \\
\hline
\end{tabular}


Order Effects Analyses for Mean Arterial Pressure

Tests of Between Subject Effects

\begin{tabular}{lllll}
\hline SS & DF & MS & F & $P$
\end{tabular}

Source of Variation

\begin{tabular}{llllll}
\hline Within Cells & 1404.82 & 35 & 41.32 & & \\
Regression & 2400.83 & 1 & 2400.83 & 58.11 & .000 \\
Task Order & 94.85 & 1 & 94.85 & 2.30 & .139 \\
\hline
\end{tabular}

Tests of Within Subjects Effects

\begin{tabular}{lllll}
\hline SS & DF & MS & F & $p$
\end{tabular}

Source of Variation

\begin{tabular}{lccccc} 
Within Cells & 734.26 & 35 & 21.60 & & \\
Regression & 14.58 & 1 & 14.58 & .68 & .417 \\
Task & 766.91 & 1 & 766.91 & 35.51 & .000 \\
Task Order BY Task & 11.89 & 1 & 11.89 & .55 & .463 \\
\hline
\end{tabular}


Order Effects Analyses for Low Frequency Heart Rate Variability

Tests of Between Subject Effects

\begin{tabular}{lllll}
\hline SS & DF & MS & F & $P$
\end{tabular}

Source of Variation

\begin{tabular}{lccccc}
\hline Within Cells & 7472.17 & 35 & 219.77 & & \\
Regression & 417.57 & 1 & 417.57 & 1.90 & .177 \\
Task Order & 17.51 & 1 & 17.51 & .08 & .779 \\
\hline
\end{tabular}

Tests of Within Subjects Effects

\begin{tabular}{lllll}
\hline SS & DF & MS & F & $p$
\end{tabular}

Source of Variation

\begin{tabular}{lccccc} 
Within Cells & 5769.23 & 35 & 169.68 & & \\
Regression & 21.24 & 1 & 21.24 & .13 & .726 \\
Task & 2949.46 & 1 & 2949.46 & 17.38 & .000 \\
Task Order BY Task & .92 & 1 & .92 & .01 & .942 \\
\hline
\end{tabular}


Order Effects Analyses for High Frequency Heart Rate Variability

Tests of Between Subject Effects

\begin{tabular}{lllll}
\hline SS & DF & MS & F & $P$
\end{tabular}

Source of Variation

\begin{tabular}{llllll}
\hline Within Cells & 6230.75 & 35 & 183.26 & & \\
Regression & 6878.20 & 1 & 6878.20 & 37.53 & .000 \\
Task Order & 18.54 & 1 & 18.54 & .10 & .752 \\
\hline
\end{tabular}

Tests of Within Subjects Effects

\begin{tabular}{lllll}
\hline SS & DF & MS & F & $p$
\end{tabular}

Source of Variation

\begin{tabular}{llllll}
\hline Within Cells & 3274.17 & 35 & 96.30 & & \\
Regression & 49.26 & 1 & 49.26 & .51 & .479 \\
Task & 2749.14 & 1 & 2749.14 & 28.55 & .000 \\
Task Order BY Task & 1.71 & 1 & 1.71 & .02 & .895 \\
\hline
\end{tabular}


Order Effects Analyses for RMSSD

Tests of Between Subject Effects

\begin{tabular}{lllll}
\hline SS & DF & MS & F & $P$
\end{tabular}

Source of Variation

\begin{tabular}{llllll}
\hline Within Cells & 9536.40 & 35 & 280.48 & & \\
Regression & 64302.01 & 1 & 64302.01 & 229.26 & .000 \\
Task Order & 230.87 & 1 & 230.87 & .82 & .371 \\
\hline
\end{tabular}

\begin{tabular}{|c|c|c|c|c|c|}
\hline \multirow[t]{2}{*}{ Tests of Within Subjects Effects } & & & & & \multirow[b]{2}{*}{$p$} \\
\hline & SS & DF & MS & $\mathrm{F}$ & \\
\hline \multicolumn{6}{|l|}{ Source of Variation } \\
\hline Within Cells & 7492.69 & 35 & 220.37 & & \\
\hline Regression & 224.94 & 1 & 224.94 & 1.02 & .319 \\
\hline Task & 2755.53 & 1 & 2755.53 & 12.50 & .001 \\
\hline Task Order BY Task & 247.75 & 1 & 247.75 & 1.12 & 296 \\
\hline
\end{tabular}




\section{Appendix F}

Mindfulness Level by Task Type by Repeated Measures Analysis for Heart Rate (bpm) Tests of Between Subject Effects

\begin{tabular}{lllll}
\hline SS & DF & MS & F & $P$
\end{tabular}

Source of Variation

\begin{tabular}{lllllll}
\hline Within Cells & 1170.88 & 35 & 33.45 & & & \\
Regression & 5736.18 & 1 & 5736.18 & 171.47 & .000 \\
Mindfulness Level & 3.97 & 1 & 3.97 & .12 & .732 \\
\hline
\end{tabular}

Tests of Within Subjects Effects

\begin{tabular}{lllll}
\hline $\mathrm{SS}$ & $\mathrm{DF}$ & $\mathrm{MS}$ & $\mathrm{F}$ & $p$
\end{tabular}

Source of Variation

\begin{tabular}{|c|c|c|c|c|c|}
\hline Within Cells & 339.17 & 35 & 9.69 & & \\
\hline Regression & .72 & 1 & .72 & .97 & .787 \\
\hline Task Type & 1526.49 & 1 & 1526.49 & 157.52 & .000 \\
\hline Mindfulness Level BY Task Type & 22.16 & 1 & 22.16 & 2.29 & .139 \\
\hline
\end{tabular}


Mindfulness Level by Task Type by Repeated Measures Analysis for Heart Rate (R-R interval) Tests of Between Subject Effects

\begin{tabular}{lllll}
\hline SS & DF & MS & F & $p$ \\
\hline
\end{tabular}

Source of Variation

\begin{tabular}{llllll}
\hline Within Cells & $128,303.50$ & 35 & 3665.81 & & \\
Regression & $605,0181.15$ & 1 & $605,0181.15$ & 165.09 & .000 \\
Mindfulness Level & 1979.53 & 1 & 1979.53 & .54 & .467 \\
\hline
\end{tabular}

Tests of Within Subjects Effects

$\begin{array}{lllll}\mathrm{SS} & \mathrm{DF} & \mathrm{MS} & \mathrm{F} & p\end{array}$

Source of Variation

\begin{tabular}{llllll}
\hline Within Cells & 40442.61 & 35 & 1155.50 & & \\
Regression & 116.22 & 1 & 116.22 & .10 & .75 \\
Task Type & 129215.56 & 1 & 129215.56 & 113.83 & .000 \\
Mindfulness Level BY Task & 4037.78 & 1 & 4037.78 & 3.49 & .07 \\
Type & & & & &
\end{tabular}


Mindfulness Level by Task Type by Repeated Measures Analysis for Systolic Blood Pressure Tests of Between Subject Effects

$\begin{array}{lllll}\text { SS } & \text { DF } & \text { MS } & \text { F } & P\end{array}$

Source of Variation

\begin{tabular}{lccccc}
\hline Within Cells & 1162.29 & 35 & 34.18 & & \\
Regression & 9444.58 & 1 & 9444.58 & 276.28 & .000 \\
Mindfulness Level & 409.65 & 1 & 409.65 & 11.98 & .001 \\
\hline
\end{tabular}

\begin{tabular}{llllll}
\hline Tests of Within Subjects Effects & \multicolumn{7}{c}{} & \\
& SS & DF & MS & F & $P$ \\
\cline { 2 - 6 } & & & & & \\
Source of Variation & 963.46 & 35 & 28.34 & & \\
\hline Within Cells & 18.14 & 1 & 18.14 & .64 & .429 \\
Regression & 1491.91 & 1 & 1491.91 & 52.65 & .000 \\
Task Type & 16.42 & 1 & 16.42 & .58 & .452 \\
Mindfulness Level BY Task Type & & & & & \\
\hline
\end{tabular}


Mindfulness Level by Task Type by Repeated Measures Analysis for Diastolic Blood Pressure Tests of Between Subject Effects

\begin{tabular}{llllll}
\hline & SS & DF & MS & F & $P$ \\
\cline { 2 - 6 } Source of Variation & & & & & \\
\hline Within Cells & 1703.08 & 35 & 50.09 & & \\
Regression & 3575.52 & 1 & 3575.52 & 71.38 & .000 \\
Mindfulness Level & .82 & 1 & .82 & .02 & .899 \\
\hline
\end{tabular}

\begin{tabular}{|c|c|c|c|c|c|}
\hline \multicolumn{6}{|l|}{ Tests of Within Subjects Effects } \\
\hline & SS & $\mathrm{DF}$ & MS & $\mathrm{F}$ & $P$ \\
\hline \multicolumn{6}{|l|}{ Source of Variation } \\
\hline Within Cells & 927.04 & 35 & 27.27 & & \\
\hline Regression & 48.18 & 1 & 48.18 & 1.77 & .193 \\
\hline Task Type & 476.47 & 1 & 476.47 & 17.47 & .000 \\
\hline Mindfulness Level BY Task Type & 98.35 & 1 & 98.35 & 3.61 & .066 \\
\hline
\end{tabular}


Mindfulness Level by Task Type by Repeated Measures Analysis for Mean Arterial Pressure Tests of Between Subject Effects

\begin{tabular}{llllll}
\hline & SS & DF & MS & F & $P$ \\
\cline { 2 - 6 } Source of Variation & & & & & \\
\hline Within Cells & 1458.37 & 35 & 42.89 & & \\
Regression & 2454.61 & 1 & 2454.61 & 57.23 & .000 \\
Mindfulness Group & 41.29 & 1 & 41.29 & .96 & .333 \\
\hline
\end{tabular}

\begin{tabular}{|c|c|c|c|c|c|}
\hline \multicolumn{6}{|c|}{ Tests of Within Subjects Effects } \\
\hline & $\mathrm{SS}$ & DF & MS & $\mathrm{F}$ & $P$ \\
\hline \multicolumn{6}{|l|}{ Source of Variation } \\
\hline Within Cells & 719.21 & 35 & 21.15 & & \\
\hline Regression & 20.93 & 1 & 20.93 & .99 & .327 \\
\hline Task & 782.22 & 1 & 782.22 & 36.98 & .000 \\
\hline Mindfulness BY Task & 26.94 & 1 & 26.94 & 1.27 & .267 \\
\hline
\end{tabular}


Mindfulness Level by Task Type by Repeated Measures Analysis for Low Frequency Heart Rate Variability

Tests of Between Subject Effects

$\begin{array}{lllll}\text { SS } & \text { DF } & \text { MS } & \text { F } & P\end{array}$

Source of Variation

\begin{tabular}{lcccccc}
\hline Within Cells & 6927.42 & 35 & 203.75 & & \\
Regression & 617.99 & 1 & 617.99 & 3.03 & .091 \\
Mindfulness Level & 562.26 & 1 & 562.26 & 2.76 & .106 \\
\hline
\end{tabular}

Tests of Within Subjects Effects

$\begin{array}{lllll}\text { SS } & \text { DF } & \text { MS } & \text { F } & P\end{array}$

Source of Variation

Within Cells

$\begin{array}{lll}5556.56 & 35 & 163.43\end{array}$

Regression

$\begin{array}{lll}57.37 & 1 & 57.37\end{array}$

.35

.557

Task Type

$3153.72 \quad 1 \quad 3153.72$

$19.30 \quad .000$

Mindfulness Level BY Task Type

213.59

$1 \quad 213.59$

$1.31 \quad .261$ 
Mindfulness Level by Task Type by Repeated Measures Analysis for High Frequency Heart Rate Variability

Tests of Between Subject Effects

$\begin{array}{lllll}\text { SS } & \text { DF } & \text { MS } & \text { F } & P\end{array}$

Source of Variation

\begin{tabular}{lllllll}
\hline Within Cells & 6170.89 & 35 & 181.50 & & & \\
Regression & 6142.76 & 1 & 6142.76 & 33.85 & .000 \\
Mindfulness Level & 78.40 & 1 & 78.40 & .43 & .515 \\
\hline
\end{tabular}

Tests of Within Subjects Effects

$\begin{array}{lllll}\text { SS } & \text { DF } & \text { MS } & \text { F } & P\end{array}$

Source of Variation

\begin{tabular}{lccccc}
\hline Within Cells & 3121.77 & 35 & 91.82 & & \\
Regression & 34.16 & 1 & 34.16 & .37 & .546 \\
Task Type & 2672.07 & 1 & 2672.07 & 29.10 & .000 \\
Mindfulness Level BY Task Type & 154.10 & 1 & 154.10 & 1.68 & .204 \\
\hline
\end{tabular}


Mindfulness by Task Type by Repeated Measures Analysis for RMSSD

Tests of Between Subject Effects

\begin{tabular}{llllll}
\hline & SS & DF & MS & F & $P$ \\
\cline { 2 - 6 } Source of Variation & & \multicolumn{7}{c}{ M } & & & \\
\hline Within Cells & 9233.65 & 35 & 271.58 \\
Regression & 62526.77 & 1 & 62526.77 & 230.24 & .000 \\
Mindfulness Group & 533.63 & 1 & 533.63 & 1.96 & .170 \\
\hline
\end{tabular}

Tests of Within Subjects Effects

$\begin{array}{lllll}\text { SS } & \text { DF } & \text { MS } & \text { F } & P\end{array}$

Source of Variation

\begin{tabular}{llllll}
\hline Within Cells & 7486.16 & 35 & 220.18 & & \\
Regression & 587.88 & 1 & 587.88 & 2.67 & .111 \\
Task & 3202.41 & 1 & 3202.41 & 14.54 & .001 \\
Mindfulness BY Task & 254.28 & 1 & 254.28 & 1.15 & .290 \\
\hline
\end{tabular}




\section{Footnotes}

${ }^{1}$ Analyses of covariance were used in the present study to examine the effects of task on cardiovascular reactivity while controlling for the effects of resting measurements on reactivity to stress. Though residualized change scores were proposed, it was determined during analyses that these were not appropriate measures of change to test the desired effects. The nature of residualized change scores is such that they result in normalized scores with a mean equal to zero, with change scores ranging from approximately negative three to positive three. These are useful measures of change that perfectly eliminate the effects of resting values. Unfortunately, residualized change scores computed for each task do not permit an analysis of task differences. Because one of the purposes of this study was to examine differences between sensory rejection and sensory intake tasks, analysis of covariance was the more appropriate statistical strategy. 


\section{CURRICULUM VITAE}

Paula R. Prentice

Updated: December 7, 2009

Clinical Psychology Doctoral Student

Behavioral and Biomedical Sciences Predoctoral Trainee

Department of Psychology

West Virginia University

\section{PERSONAL DATA}

Work address: Department of Psychology

Office 1200 Life Science Building

West Virginia University

Morgantown, WV 26506

Phone: $\quad$ (607) 372-9708 (cell)

Email: $\quad$ Paula.Prentice@mail.wvu.edu

\section{EDUCATION}

Ph.D. Clinical Psychology

West Virginia University, Morgantown, WV

M.S. Clinical Psychology

West Virginia University, Morgantown, WV

B.S. Biology and Psychology

University at Albany, SUNY, Albany NY

A.S.

Broome Community College, Binghamton, NY

\section{RESEARCH EXPERIENCE}

Graduate Trainee

Research Training Program

Behavioral and Biomedical Sciences

NIH 5T32GM081741-02

Graduate Research Assistant

Supervisor: Kevin Larkin, Ph.D.

Physiology Laboratory

Department of Psychology

West Virginia University
Anticipated May 2012

December 2009

May 2007

May 2004

July 2009 - July 2010

August 2007 - Present Behavioral 
Research Assistant June 2009 - Present

Supervisor: Jefferson Frisbee, Ph.D.

Department of Physiology and Pharmacology

West Virginia University

Graduate Research Assistant

August 2009 - Present

Supervisor: Amy Fiske, Ph.D.

Mental Health and Aging Lab

Department of Psychology

West Virginia University

Research Assistant

Supervisor: Sharon Danoff-Burg, $\mathrm{PhD}$

August 2006 - May 2007

Psychology Laboratory

Health

at Albany, SUNY

\section{PROFESSIONAL EXPERIENCE}

Faculty-Nominated Student Representative

Graduate Training Committee, Department of Psychology

May 2009- Present

Campus Representative

American Psychological Association of Graduate Students (APAGS)

May 2009- Present

Student Representative

August 2009- Present

Clinical Training Committee, Department of Psychology

Graduate Student Administrator

July 2008 - July 2009

Quin Curtis Psychological Services Center

West Virginia University

Graduate Student Therapist

Quin Curtis Psychological Services Center and Family Medicine

August 2007 - Present

West Virginia University

Conduct regular outpatient therapy sessions with clinical populations, including individuals experiencing anxiety disorders, depression, and health complaints.

Graduate Teaching Assistant

August 2007 - May 2008

West Virginia University

Instruct and aid in the design of a Psychology 101 undergraduate course.

Graduate Teaching Assistant Supervisor

August 2007 - May 2008

West Virginia University 


\section{MANUSCRIPTS}

Prentice, P.R., Ragatz, L.L., Nadorff, M., St. Peter Pipkin, C., Larkin, K.T. Are We Asking the Right Questions? The relation between student word choice and teaching evaluations. (under review).

Prentice, P.R., Whited, M., Kyle, B.K., \& Larkin, K.T. The value of comprehensive mindfulness skills: Bidirectional relations between mindfulness subscales and health anxiety (Manuscript in progress)

Prentice, P.R. \& Wheat, A. The predictive value of impulsivity in relation to indoor and outdoor tanning. (Manuscript in progress)

\section{PRESENTATIONS}

Prentice, P.R., Wheat, A.,Stahl, S., \& Larkin, K. T. (2010, April). The Dark Side of Impulsivity: The predictive value of impulsivity in relation to tanning. Paper accepted for presentation as part of a symposium, Impulsive Choice and Health Behavior: Emerging Applications for the Measurement of Delay Discounting, Amanda Wheat, chair, $31^{\mathrm{st}}$ Annual Meeting of the Society of Behavioral Medicine, Seattle, Washington.

Prentice, P. R., Wheat, A., Goulet, C., \& Larkin, K. T. (2010, April).Mindfulness and Prevention: Acting with Awareness and Alcohol Use. Poster accepted for presentation at the $31^{\text {st }}$ Annual Meeting of the Society of Behavioral Medicine, Seattle, Washington.

Prentice, P.R., Whited, M., Penwell, L., Larkin, K.T., Ale, C.M., Kemmner, C., Sundin, K., \& Wheat, A.L. (2009, March). Gender Role Moderates Heart Rate Variability Response and Eye Contact during Interpersonal Stress. Poster presented at the annual meeting of the American Psychosomatic Society, Chicago, IL.

Prentice, P.R., Kyle, B.N., Wheat, A., \& Larkin, K.T. (2008, November). Predicting Health Anxiety from Mindfulness Subscales. Poster presented at the annual meeting of the Association for Behavioral and Cognitive Therapies (Behavioral Medicine Special Interest Group), Orlando, FL.

Kyle, B.N., Larkin, K.T., \& Prentice, P.R. (2008, November). Two measures of informational coping style and their relation to health anxiety. Poster presented at the annual meeting of the Association for Behavioral and Cognitive Therapies (Behavioral Medicine Special Interest Group), Orlando, FL.

Prentice, P. R., Ragatz, L. L., Nadorff, M., St. Peter Pipkin, C., \& Larkin, K. T. $\quad$ (2008, June). How to make your students like you: Qualities students look for in their instructors. Poster presented at the annual meeting of the Eastern Conference on the Teaching of Psychology, Harrisonburg, VA. 
Prentice, P. R., Ragatz, L. L., Nadorff, M., St. Peter Pipkin, C., \& Larkin, K. T. (2008, May). Sex bias in teaching evaluations: student ratings and word choice. Poster presented at the annual meeting of the Association for Psychological Science, Chicago, IL.

Wheat, A. \& Prentice, P.R. (2008, May). White Coat Effects as a Predictor of State Anxiety. Poster presented at the annual meeting of the Association for Psychological Science, Chicago, IL.

\section{RESEARCH IN PROGRESS}

Prentice, P.R. (Thesis in progress; data analysis). Dispositional mindfulness and cardiovascular reactivity to sensory intake and sensory rejection tasks.

Prentice, P.R., Ragatz, L.L., Nadorff, M., St. Peter Pipkin, C., Larkin, K.T. (data collection stage). Behavioral validation of the Teacher Behavior Checklist.

\section{REVIEWING EXPERIENCE}

Co-Reviewer:

Applied Psychophysiology and Biofeedback

International Journal of Behavioral Medicine

The Journal of Positive Psychology

\section{AWARDS AND GRANTS}

Research Grant: Received \$750 from the West Virginia University Department of Psychology Alumni Fund to fund thesis research

Research Grant: Received \$700 from West Virginia University for research travel expenses. Research Grant: Received $\$ 700$ from West Virginia University for research travel expenses

\section{MEMBERSHIP IN PROFESSIONAL ORGANIZATIONS}

American Psychosomatic Society

American Psychological Association

American Psychological Association: Division 38 Health Psychology

Association for Psychological Science

Association for Behavioral and Cognitive Therapies

Phi Beta Kappa

Psi Chi Psychology Honor Society

Phi Theta Kappa

\section{SCHOLASTIC HONORS}




\section{University at Albany}

University at Albany Presidential Scholar

V. Smith Science Scholar

Craig Scholar

at Albany Dean's List

August 2004 - May 2007 Ben August 2005 - May 2007 Edna

August 2006 - May 2007 University August 2004 - May 2007

\section{Broome Community College}

Phi Theta Kappa International Honor Society

Scholarship for Excellence in Liberal Arts

President's List

\section{SERVICE EXPERIENCE}

Stress Management Seminar Leader

Friendship Room, Morgantown, WV

Habitat for Humanity

Ronald McDonald House
August 2002 - Present

Received May 2004 August 2002 - May 2004

\author{
August 2008 \\ August 2004- August 2005 \\ August 2004
}

